NBER WORKING PAPER SERIES

TURBULENCE, FIRM DECENTRALIZATION AND GROWTH IN BAD TIMES

\author{
Philippe Aghion \\ Nicholas Bloom \\ Brian Lucking \\ Raffaella Sadun \\ John Van Reenen \\ Working Paper 23354 \\ http://www.nber.org/papers/w23354 \\ NATIONAL BUREAU OF ECONOMIC RESEARCH \\ 1050 Massachusetts Avenue \\ Cambridge, MA 02138 \\ April 2017, Revised October 2017
}

We would like to thank Ufuk Akcigit, Laura Alfaro, Richard Blundell, Erik Brynjolfsson, Gabriel Chodorow-Reich, Bob Gibbons, Rebecca Henderson, Bengt Holmstrom, Caroline Hoxby, Guy Laroque, Eddie Lazear, Kristina McElheran, Antoinette Schoar, David Thesmar, Jean Tirole and participants in seminars in the AEA, UC Berkeley, Columbia, Harvard, MIT, Northwestern, Stanford and Toronto for helpful discussions. The Economic and Social Research Centre, European Research Council, Kauffman Foundation, National Science Foundation and Sloan Foundation have all provided generous funding. Any opinions and conclusions expressed herein are those of the authors and do not necessarily represent the views of the U.S. Census Bureau or the National Bureau of Economic Research. All results have been reviewed to ensure that no confidential information is disclosed.

NBER working papers are circulated for discussion and comment purposes. They have not been peer-reviewed or been subject to the review by the NBER Board of Directors that accompanies official NBER publications.

(C) 2017 by Philippe Aghion, Nicholas Bloom, Brian Lucking, Raffaella Sadun, and John Van Reenen. All rights reserved. Short sections of text, not to exceed two paragraphs, may be quoted without explicit permission provided that full credit, including $\odot$ notice, is given to the source. 
Turbulence, Firm Decentralization and Growth in Bad Times

Philippe Aghion, Nicholas Bloom, Brian Lucking, Raffaella Sadun, and John Van Reenen

NBER Working Paper No. 23354

April 2017, Revised October 2017

JEL No. E0

\begin{abstract}
What is the optimal form of firm organization during "bad times"? We present a model of delegation within the firm to show that the effect is ambiguous. The greater turbulence following macro shocks may benefit decentralized firms because the value of local information increases (the "localist" view). On the other hand, the need to make tough decisions may favor centralized firms (the "centralist" view). Using two large micro datasets on firm decentralization from ten OECD countries and US administrative data, we find that firms that delegated more power from the Central Headquarters to local plant managers prior to the Great Recession out-performed their centralized counterparts in sectors that were hardest hit by the subsequent crisis. Using direct measures of turbulence based on product churn and stock market volatility, we show that the localist mechanism dominates. This conclusion is robust to alternative explanations such as managerial fears of bankruptcy and changing coordination costs. Although delegation is better suited to some environments than others, countries with more decentralized firms (like the US) weathered the 2008-09 Great Recession better: these organizational differences account for about $15 \%$ of international differences in post-crisis GDP growth.

$\begin{array}{ll}\begin{array}{l}\text { Philippe Aghion } \\ \text { College de France }\end{array} & \begin{array}{l}\text { Raffaella Sadun } \\ \text { Harvard Business School } \\ \text { M Rue D'Ulm }\end{array} \\ \text { 75005 Paris } & \begin{array}{l}\text { Soldiers Field } \\ \text { Boston, MA 02163 } \\ \text { and NBER }\end{array} \\ \text { paghCE } & \begin{array}{l}\text { rsadun@ @bs.edu } \\ \text { paghion@fas.harvard.edu }\end{array} \\ \text { Nicholas Bloom } & \text { John Van Reenen } \\ \text { Stanford University } & \text { Department of Economics, E62-518 } \\ \text { Department of Economics } & \text { MIT } \\ \text { 579 Serra Mall } & 77 \text { Massachusetts Avenue } \\ \text { Stanford, CA 94305-6072 } & \text { Cambridge, MA 02139 } \\ \text { and NBER } & \text { and NBER } \\ \text { nbloom@ stanford.edu } & \text { vanreene@ mit.edu } \\ \text { Brian Lucking } & \\ \text { Department of Economics } & \\ \text { Stanford University } & \\ \text { Stanford, CA 94305 } & \\ \text { blucking@ stanford.edu } & \end{array}$
\end{abstract}




\title{
Turbulence, Firm Decentralization and Growth in Bad Times
}

\author{
Philippe Aghion; Nicholas Bloom† Brian Lucking; Raffaella Sadun ${ }^{\S}$ and John Van Reenen $₫$
}

October 25,2017

\begin{abstract}
What is the optimal form of firm organization during "bad times"? We present a model of delegation within the firm to show that the effect is ambiguous. The greater turbulence following macro shocks may benefit decentralized firms because the value of local information increases (the "localist" view). On the other hand, the need to make tough decisions may favor centralized firms (the "centralist" view). Using two large micro datasets on firm decentralization from ten OECD countries and US administrative data, we find that firms that delegated more power from the Central Headquarters to local plant managers prior to the Great Recession out-performed their centralized counterparts in sectors that were hardest hit by the subsequent crisis. Using direct measures of turbulence based on product churn and stock market volatility, we show that the localist mechanism dominates. This conclusion is robust to alternative explanations such as managerial fears of bankruptcy and changing coordination costs. Although delegation is better suited to some environments than others, countries with more decentralized firms (like the US) weathered the 2008-09 Great Recession better: these organizational differences account for about $15 \%$ of international differences in post-crisis GDP growth.
\end{abstract}

JEL No. O31, O32, O33, F23

Keywords: decentralization, growth, turbulence, Great Recession

Acknowledgments: We would like to thank Ufuk Akcigit, Laura Alfaro, Richard Blundell, Erik Brynjolfsson, Gabriel Chodorow-Reich, Bob Gibbons, Rebecca Henderson, Bengt Holmstrom, Caroline Hoxby, Guy Laroque, Eddie Lazear, Kristina McElheran, Antoinette Schoar, David Thesmar, Jean Tirole and participants in seminars in the AEA, UC Berkeley, Columbia, Harvard, MIT, Northwestern, Stanford and Toronto for helpful discussions. The Economic and Social Research Centre, European Research Council, Kauffman Foundation, National Science Foundation and Sloan Foundation have all provided generous funding.

Disclaimer: Any opinions and conclusions expressed herein are those of the authors and do not necessarily represent the views of the U.S. Census Bureau. All results have been reviewed to ensure that no confidential information is disclosed.

\footnotetext{
*College de France, LSE and Centre for Economic Performance,

${ }^{\dagger}$ Stanford University, Centre for Economic Performance, NBER and CEPR

${ }^{\ddagger}$ Stanford University.

$\S$ Harvard University, Centre for Economic Performance, NBER and CEPR

${ }^{\top}$ MIT, Centre for Economic Performance, NBER and CEPR
} 


\section{Introduction}

What makes firms more resilient to large negative macro shocks? A recent literature has focused on firms' technological, financial and governance structures as possible factors affecting their ability to cope with sudden changes in external conditions ${ }^{1}$, but much less is known about the role of firm organization. This paper focuses on how a specific organizational aspect of a firm: the extent to which decision-making is decentralized down from headquarters to plant managers, affects performance during an economic crisis. This has particular relevance following the Great Recession of 2009-08, which generated a debate over how best to organize for "recovery and survival". One common argument is that centralized firms were best equipped to survive the recession because of the importance of cost cutting which, due to conflicting interests within the firm, is best directed from corporate headquarters (the "centralist" view). An alternative "localist" view is that recessions are periods of rapid change, and being decentralized provides firms with the necessary flexibility to respond to turbulent business conditions. ${ }^{2}$

To investigate these issues, we created two new panel datasets with explicit measures of decentralization measured prior to the Great Recession. One dataset, the World Management Survey (WMS) has firm level data across ten OECD countries (France, Germany, Greece, Italy, Japan, Poland, Portugal Sweden, the UK and US). The other dataset, the Management and Organizational Practices Survey (MOPS), is an establishment level dataset covering U.S. manufacturing plants. ${ }^{3}$ which we constructed in partnership with the Census Bureau. We combine these datasets with firm and plant performance data before and after the 2009-08 crisis.

In order to guide the empirical analysis, we develop a model of firm decision-making building on the Aghion and Tirole (1997) approach. The model illustrates two countervailing effects of decentralization on firm performance during a crisis. On the one hand, a crisis is more likely to reduce the level of congruence between the CEO and the plant manager-for example, tough decisions on closing down projects and laying off staff will be resisted by local managers. At the same time, however, a crisis can also increase turbulence/uncertainty, thus making local information more valuable. In this case, a crisis would actually make decentralization more attractive, since it enables firms to better understand and adapt to the turbulent business environment. This result is akin to those emerging from a wide class of models where higher turbulence and uncertainty increase the value of local knowledge and the benefits of decentralization. The net effect of

\footnotetext{
${ }^{1}$ For example, see Aghion, Askenazy, Berman, Cette, and Eymard (2012) on technology; Chodorow-Reich (2014) on financial structure and Alfaro and Chen (2012) or D'Aurizio, Oliviero and Romano (2015) on governance.

${ }^{2}$ Support for these starkly different views can be found, for example, in reports by the Economist Intelligence Unit. In the depths of the Great Recession in June 2009 they wrote in favor of centralization during the crisis: "Firms should be centralizing their decision-making processes. [...] In a recession investments and other decisions are scrutinized more carefully by senior management and a greater emphasis is placed on projects that provide benefits across the enterprise rather than individual units." Yet three months later in August the same publication supported decentralization: "Companies have to deal with dramatically more uncertainty, complexity and ambiguity in the current recession. Success does not come from centralization. True flexibility arises when those who are closest to customers are empowered to respond to constant shifts in demand, preferences and attitudes."

${ }^{3}$ We use the terms "establishment" and "plant" interchangeably throughout.
} 
decentralization on firm performance is thus theoretically ambiguous.

We then turn to the empirical analysis and find compelling evidence that, in sectors that were exogenously hit harder by the crisis, decentralized firms outperformed their centralized rivals in terms of survival chances as well as in their growth of sales, productivity and profits. We use several measures of the shock, including changes in trade patterns (exports in an establishment's industry by country cell) and a pre-recession measure of product durability to measure the shock (durable goods industries suffer more in recessions as consumers can postpone purchases). Our findings are robust to placebo tests, and a wide range of controls.

Consistent with our model, we show that our empirical results are driven by the fact that the industries which had the most severe downturns during the Great Recession also had the largest increase in turbulence. ${ }^{4}$ To show this, we employ a novel industry level measure of turbulence, the rate of new product additions and subtractions (product churn), which we built from the US Census of Manufactures ten digit product data. As shown in Bernard and Okubo (2015), product churn rises sharply during recessions-in a crisis establishments both destroy more existing products and also create more new products. ${ }^{5}$ Using this measure on the US Census sample, we find that decentralization significantly protected establishments from the downturn in industries which had a bad shock, and an increase in product churn. We validate these results using an alternative measure of turbulence based on the stock market volatility, which is available for the international WMS sample as well as the US MOPS.

Alternative explanations of our results based on reduced agency problems, financial conditions, lower coordination costs, omitted variables and other factors do not seem so consistent with the data. Finally, although organizational change is slow (we show evidence of large adjustment costs), firms subject to large negative shocks appear more likely to decentralize.

Overall, our paper suggests that the internal organization of firms may serve as an important mediating factor through which macroeconomic shocks affect firm performance and, ultimately, growth.

Our paper builds on an extensive prior literature. The benefits of exploiting local knowledge harks back to a classic economic debate over economic systems between Lange (1936) and Von Hayek (1945). Lange argued that a centralized socialist economy would outperform a decentralized market economy, partly because the central planner could co-ordinate better, for example by setting prices to internalize externalities. By contrast, Hayek argued that it was impossible to aggregate all the local knowledge of agents, and it was both more efficient (and just) to allow individuals to make their decentralized choices based on the their local information. Modern organizational economics builds upon these trade-offs within a firm rather than across

\footnotetext{
${ }^{4}$ Bloom, Floetotto, Jaimovich, Saporta-Eksten and Terry (2016) shows a large variety of datasets that suggest that turbulence and uncertainty rise in downturns.

${ }^{5}$ Contrary to Bernard and Okubo (2015), Broda and Weinstein (2010) report a pro-cyclical product churn. However, they have a a very different focus-looking at the net change in the product offering in retail stores (the number of new bar code products sold less current products no-longer sold)-and a different time period (1994 and 1999-2003) spanning one mild recession. In contrast, our measure is gross product churn (new products plus dropped products), is built on manufacturing establishment production data, and spans 15 years from 1997-2012, exploiting aggregate and industry variation.
} 
the economy as a whole. On the theory side, our paper relates to the literature on decentralization within the firm (see Gibbons, Matouschek and Roberts, 2013, or Garicano and Rayo, 2016 for recent surveys) and incomplete contracts (see Gibbons and Roberts, 2013, and Aghion, Bloom and Van Reenen, 2014 for surveys). In particular, Hart and Moore (2005) analyze the optimal allocation of authority in multi-layer hierarchies. Dessein (2002) analyzes how the allocation of control can help incorporate the agent's information into decision-making in a situation where the agent has private information. ${ }^{6}$

Our paper also relates to the existing empirical literature on decentralization and its determinants. For example, Rajan and Wulf (2006) and Blundell et al. (2016) document a movement towards flatter organizations and decentralized firms in the US and UK respectively. Caroli and Van Reenen (2001) and Bresnahan, Brynjolfsson and Hitt (2002) point at positive correlations between decentralization and both human capital and information technology. Guadalupe and Wulf (2009) argue that the Canadian-US Free Trade Agreement (FTA) in 1989 constitutes an exogenous increase in competition for US firms in the industries where tariffs were removed and this caused greater delayering and decentralization. Closest to our analysis is Acemoglu et al. (2007), whose model assumes firms can learn about the outcome of an investment decision from observing other firms. Hence, in sectors with more heterogeneity/turbulence or where the firm is closer to the performance frontier (so that learning is more limited) decision-making control should be more decentralized. In the contract literature, Prendergast (1982) suggested that the "puzzle" of performance pay in uncertain and turbulent environments (where higher risk should make the agent less willing to accept a high-powered contract) could be because of the need to exploit local information more effectively. Similarly, in the firm boundaries literature, Lafontaine and Slade (2007) also suggest that a similar puzzle over the lack of a negative impact of turbulence on franchising (vs. direct control), could again be related to the need to exploit the franchiser's superior local knowledge, which is more important in such environments. None of these papers, however, look at the interplay between firm decentralization, shocks and turbulence which is the center of our analysis. ${ }^{7}$

The paper is organized as follows. Section 2 presents the model, Section 3 the data and methodology and Section 4 establishes our main empirical finding that in times of crisis decentralized firms outperform their centralized counterparts. Section 5 considers extensions, showing that volatility seems to matter rather than other mechanisms such as changing levels of congruence and Section 7 concludes.

\footnotetext{
${ }^{6}$ In contrast to Aghion and Tirole (1997), there is no information acquisition effort by the agent or the principal, therefore in Dessein's model the allocation of authority is not so much a tool to motivate the agent (as in Aghion and Tirole) or give a supplier incentives to make relationship specific investments (as in Grossman and Hart, 1986). A key insight in Dessein (2002) is that in a world with asymmetric information and contractual incompleteness, the delegation of authority from a Principal to an Agent is often the best way to elicit the agent's private information.

${ }^{7}$ Bradley et al (2011) report a positive relationship between firm independence-which they interpret as a proxy for greater autonomy in resource allocation decisions-and firm survival during downturns using Swedish data.
} 


\section{A simple model}

To guide the empirical analysis of the relationship between firm performance and decentralization during a crisis, we develop a simple model based upon Aghion and Tirole (1997). The key idea is that there is a trade off between incentives and local information. Possible misalignment of interests between the CEO and the plant manager favors centralization. But the plant manager is likely to have better local information than the CEO, which is a force for decentralization. A negative shock may affect the returns to decentralization in two, opposite, ways. First, it may reduce the benefits of decentralization, by increasing the possible misalignment of interests between the CEO and the plant manager. Second, it may increase the benefits of decentralization by increasing the informational asymmetry between the CEO and the plant manager, and thus the value of local information.

\subsection{Basic set up}

We consider a one-period model of a firm with one principal (the $\mathrm{CEO} /$ central headquarters) and one agent (the plant manager). The CEO cares about the profitability of the business, ${ }^{8}$ whereas the plant manager wants to maximize private benefits and is not responsive to monetary incentives. ${ }^{9}$ Taking an uninformed action involves potentially disastrous outcomes, thus an action will be taken only if at least one of the two parties is informed. Also, the agent obtains private benefits only if the firm remains in business.

There are $n \geq 3$ possible actions (or projects) and at any point in time only two of them are "relevant", i.e. avoid negative payoffs to the parties. Among these two actions, one maximizes monetary profitability, one maximizes the agent's private utility. Other actions lead to very negative payoffs to both parties.

With ex ante probability $\alpha$ the agent's preferred action (conditional upon the firm remaining in business) will also be the action that maximizes profits (or monetary efficiency); this variable $\alpha$ captures the degree of congruence between the principal's preferences and the agent's preferences. If preferences coincide, then the action that maximizes the private utility of the agent also yields monetary utility $B$ to the principal; if preferences do not coincide, the action that maximizes the agent's private utility yields monetary payoff $B-k$ to the principal.

Informational assumptions: We assume that the principal knows about project payoffs with probability $p$, but does not know directly which action the agent actually performed. On the other hand, the agent is assumed to be perfectly informed about the project payoffs.

Turbulence: Suppose that the principal can obtain an early signal of forthcoming performance, e.g. a current realization of income, at some cost $C$, and can then possibly decide to fire the agent if she believes

\footnotetext{
${ }^{8}$ For simplicity, we abstract from the agency problem between the owners of the firm and the CEO. The results just rely on the plausible assumption that the CEO cares more about the overall profits of the company than the plant manager.

${ }^{9}$ This is to rule out implementation of a performance pay contract to overcome the principal-agent problem. Obviously, we could allow some incentive contracts and so long as these only partially deal with the agency problem, the mechanisms we describe here would still be at play.
} 
that the signal is due to the agent's choosing a non-profit maximizing action. In the absence of turbulence, the signal reveals the bad action choice perfectly. But the higher the degree of turbulence, the more difficult it is for the principal to infer action choice from performance.

Thus, suppose that current performance is given by

$$
y=a+\varepsilon
$$

where $a \in\left\{a_{1}, a_{2}\right\}$ denotes the agent's action choice (e.g. a decision whether or not to introduce a new product ${ }^{10}$, with $a_{1}<a_{2}$ and $\varepsilon$ is a noise term uniformly distributed on the interval $[-u, u]$.

\subsection{Solving the model}

Suppose that the plant manager takes the non-profit maximizing action $a_{1}$ (e.g. a decision which delays the introduction of a new product). The CEO will infer the action choice from observing the signal realization:

$$
y=a+\varepsilon
$$

if and only if $y \in\left[a_{1}-u, a_{2}-u\right) \cup\left(a_{1}+u, a_{2}+u\right]$ and then can correct it if she has control rights, i.e. under centralization.

By Bayes' rule the probability of the CEO guessing the action choice is:

$$
P(u)=\operatorname{Pr}\left(y \in\left[a_{1}-u, a_{2}-u\right) \cup\left(a_{1}+u, a_{2}+u\right]\right)
$$

that is:

$$
P(u)=\min \left\{\frac{2\left(a_{2}-a_{1}\right)}{a_{2}-a_{1}+2 u}, 1\right\} .
$$

The probability of guessing the correct action is clearly declining in the amount of noise parameterized by $u$. Hence, the probability that the profit-maximizing action will be taken eventually under centralization $(\Omega)$, is equal to:

$$
\Omega(u)=P(u)+(1-P(u)) \alpha
$$

where $P$ is the probability that the principal acquires the information about projects payoffs.

\footnotetext{
${ }^{10}$ Equivalently, this could be whether to drop an existing product from the portfolio or to make an investment in marketing or sales that enhances the product's value to the consumer. The key thing is that the decision has to have some irreversibility.
} 


\subsection{Centralization versus decentralization}

The ex ante CEO's payoff under decentralization, is equal to:

$$
\Pi^{d}=\alpha B+(1-\alpha)(B-k)
$$

The ex ante CEO's payoff under centralization (i.e. if the CEO delegates no authority to the plant manager), is equal to:

$$
\Pi^{c}=\Omega(u) B+[1-\Omega(u)](B-k)-C
$$

The net gain from centralization is then given by:

$$
\Delta \Pi=\Pi^{c}-\Pi^{d}=P(u)(1-\alpha) k-C .
$$

\subsection{Two countervailing effects of a bad shock}

We think of a bad shock as reducing congruence between the principal and the agent. For example, the negative shock may require cost-cutting such as closing down plants and laying off employees which will be particularly resisted by middle managers. More formally, to the extent that the principal has invested wealth in the project whereas the agent is subject to limited liability. In other words, a bad shock is likely to increase $k$. For a given level of uncertainty $u$, this will make centralization more attractive as:

$$
\frac{\partial \Delta \Pi}{\partial k}=P(u)(1-\alpha)>0
$$

There is, however, also much evidence (summarized in Bloom, Floetotto, Jaimovich, Saporta-Eksten and Terry, 2016) that negative macro shocks are usually associated with greater turbulence and uncertainty (i.e. a higher $u$ ). This makes centralization less attractive, since:

$$
\frac{\partial \Delta \Pi}{\partial u}=(1-\alpha) k P^{\prime}(u) \leq 0
$$

If the level of turbulence does not change after the occurrence of a bad shock, the overall effect of a bad shock is to make centralization unambiguously more attractive. However, if uncertainty increases with a bad shock and $k$ does not change, the bad shock makes centralization become less attractive. Hence, the impact of a bad shock is theoretically ambiguous. We will investigate empirically which effect dominates, and then return to the theory to help inform potential mechanisms. 


\section{Data Description and Measurement}

We start by describing in some detail our decentralization data since this involved an extensive new survey process. We then describe the accounting and administrative data matched with the survey-based measures of decentralization and the proxies measuring the severity of the Great Recession. We describe our measures of turbulence in Section 5 when we discuss theoretical mechanisms. More details on the data are in online Appendix A.

\subsection{Decentralization}

Cross-country data: World Management Survey (WMS) Our international decentralization data was collected in the context of the World Management Survey (WMS), a large scale project aimed at collecting high quality data on management and organizational design across firms around the world. The survey is conducted through an interview with a plant manager in medium sized manufacturing firms.

We asked four questions on decentralization from the central headquarters to the local plant manager. First, we asked how much capital investment a plant manager could undertake without prior authorization from the corporate headquarters. This is a continuous variable enumerated in national currency that we convert into dollars using PPPs. ${ }^{11}$ We also inquired on where decisions were effectively made in three other dimensions: (a) the introduction of a new product, (b) sales and marketing decisions and (c) hiring a new full-time permanent shop floor employee. These more qualitative variables were scaled from a score of 1 , defined as all decisions taken at the corporate headquarters, to a score of 5 defined as complete power ("real authority") of the plant manager. In Appendix Table A1 we detail the individual questions in the same order as they appeared in the survey. Since the scaling may vary across all these questions, we standardized the scores from the four decentralization questions to z-scores by normalizing each question to mean zero and standard deviation one. We then average across all four z-scores and then z-score the average again to have our primary measure of overall decentralization. In the same survey we collected a large amount of additional data to use as controls, including management practice information following the methodology of Bloom and Van Reenen (2007) and human resource information (e.g. the proportion of the workforce with college degrees, average hours worked, the gender and age breakdown within the firm).

We attempt to achieve unbiased survey responses to our questions by taking a range of steps. First, the survey was conducted by telephone without telling the managers they were being scored on organizational or management practices. This enabled scoring to be based on the interviewer's evaluation of the firm's actual practices, rather than their aspirations, the manager's perceptions or the interviewer's impressions. To run this "blind scoring" we used open questions (i.e. "To introduce a new product, what agreement would

\footnotetext{
${ }^{11}$ One reason that the main regressions control for size is that the value of this question might be mechanically greater for larger firms and plants.
} 
your plant need from corporate headquarters?"), rather than closed questions (e.g. "Can you introduce new products without authority from corporate headquarters?" [yes/no]) (see question in Table A1). Second, the interviewers did not know anything about the firm's financial information or performance in advance of the interview. ${ }^{12}$ Consequently, the survey tool is "double blind" - managers do not know they are being scored and interviewers do not know the performance of the firm. These manufacturing firms (the median size was 250 employees) are mostly privately held and too small to attract coverage from the business media. Third, each interviewer ran 85 interviews on average, allowing us to remove interviewer fixed effects from all empirical specifications. This helps to address concerns over inconsistent interpretation of responses. Fourth, we collected information on the interview process itself (duration, day-of-the-week), on the manager (seniority, job tenure and location), and on the interviewer (for removing analyst fixed effects and subjective reliability score). These survey metrics are used as "noise controls" to help reduce residual variation.

We decided to focus on the manufacturing sector where productivity is easier to measure than in the non-manufacturing sector. We also focused on medium sized firms, selecting a sampling frame of firms with between 50 and 5,000 workers. Very small firms have little publicly available data. Very large firms are likely to be more heterogeneous across plants. We drew a sampling frame from each country to be representative of medium sized manufacturing firms and then randomly chose the order of which firms to contact.

Each interview took an average of 48 minutes and the main wave was run in the summer of 2006 . We achieved a $45 \%$ response rate, which is very high for company surveys, because (i) the interview did not discuss firm's finances (we obtained these externally); (ii) we had the written endorsement of many official institutions like the Bundesbank, Treasury and World Bank, and (iii) we hired high quality MBA-type students. We also ran some follow up surveys in 2009 and 2010 following the same firms sampled in 2006 to form a panel which we use to look at changes in decentralization.

U.S. Census data: Management and Organizational Practices Survey (MOPS) The 2010 Management and Organizational Practices Survey (MOPS) was jointly funded by the Census Bureau and the National Science Foundation as a supplement to the Annual Survey of Manufactures (ASM). The design was based on the World Management Survey and was mailed to the establishment plant manager (see Brynjolfsson and McElheran 2016 and Bloom, Brynjolfsson, Foster, Jarmin, Saporta-Eksten and Van Reenen, 2016). The survey contained six questions on decentralization with four of these covering the same domain as WMS-plant manager autonomy over (a) capital investments, (b) hiring of full time employees, (c) product introduction and (d) sales and marketing-with two additional question on e) pay increases of at least $10 \%$, and (f) product pricing decisions. For each question, respondents were asked to choose among three options capturing where the specific decisions were made: "only at this establishment" (coded as 3), "only at

\footnotetext{
${ }^{12}$ This was achieved by selecting medium sized manufacturing firms and by providing only firm names and contact details to the interviewers (but no financial details).
} 
headquarters" (coded as 1), or "both at this establishment and at headquarters" (coded as 2). There were five choices for the question on autonomy in capital investments, starting with "Under $\$ 1,000$ " (coded as 1) up until " $\$ 1$ million or more" (coded as 5). Each of these six questions was then z-scored, and then averaged, and then z-scored again. The survey also included management practice questions and some background questions on the establishment and respondent. ${ }^{13}$ The respondent was asked about conditions in 2010 and 2005 .

The MOPS survey was sent to all ASM establishments in the ASM mail-out sample. Overall, 49,782 MOPS surveys were successfully delivered, and 37,177 responses were received, yielding a response rate of $78 \%$. The Organization Module of MOPS is only for plants where headquarters is off site - plants with headquarters on site are told to skip this section - which takes the sample to about 20,000 plants. We further require the sample to match to the $2006 \mathrm{ASM}$ and $2009 \mathrm{ASM}$ to calculate the main dependent variable (growth in sales) which brings the sample down to 8,774 plants. ${ }^{14}$ Table A2 shows how our various samples are derived from the universe of establishments.

\subsection{Accounting data}

Cross-country WMS data We build firm level measures of sales, employment, capital, profits and materials using accounting data extracted from Bureau Van Dijk's ORBIS. These are digitized versions of company accounts covering very large samples (close to the population in most of our countries) of private and publicly listed firms. In our baseline specifications we estimate in three-year (annualized) growth rates. We are able to build firm level measure of sales growth for at least one year for 1,330 out of the 2,351 firms with decentralization data in 2006.

U.S. MOPS data In addition to our decentralization data, we also use data from other Census and nonCensus data sets to create our measures of performance (growth in sales, productivity, and profitability). We use establishment level data on sales, value-added and labor inputs from the ASM to create measures of growth and labor productivity. As described in more detail in Appendix A, we also combined the plant-level capital stock data from the Census of Manufactures with investment data from the ASM and applied the perpetual inventory method to construct annual capital stocks. Finally, we measure plant profitability using profits as a percent of capital stock, with plant-level profits defined as sales less total salaries and wages, material costs, and rental expenses.

\footnotetext{
${ }^{13}$ The full questionnaire is available on http://www.census.gov/mod/mops/how_the_data_are_collected/MP10002 16NOV10.pdf.

${ }^{14}$ The ASM is a stratified randomly sampled rotating 4 year panel, so many plants are not included across panels, which accounts for over $90 \%$ of this drop in sample size
} 


\subsection{Measuring the Great Recession}

Our baseline measure of the intensity of impact of the Great Recession ("SHOCK") at an industry by country cell level comes from the UN COMTRADE database of world trade. This is an international database of six-digit product level information on all bilateral imports and exports between any given pairs of countries. We aggregate COMTRADE data from its original six-digit product level to three-digit US SIC-1987 level using the Pierce and Schott (2010) concordance. We deflate the industry and country specific export value series by a country and year specific CPI from the OECD to measure "real exports." 15

For the U.S. MOPS data we are able to construct a more detailed "SHOCK" variable which varies at the establishment level. Specifically, we use pre-recession product level revenue data from the 2006 ASM to measure each establishment's distribution of sales across 7 digit NAICS products before the onset of the Great Recession. We then aggregate the Longitudinal Firm Trade Transactions Database (LFTTD), which contains the universe of import and export transactions for U.S. firms, to the product-year level. By matching each establishment's pre-recession distribution of sales across products to product level export growth, we are able to obtain a more precise measure of the intensity of the Great Recession which measures export growth in the products which the establishment produces. All results from the U.S. MOPS data use this establishment specific formulation of the "SHOCK" measure. ${ }^{16}$ The plant-specific shock is advantageous in that it addresses an important potential bias arising from mismeasurement of the relevant economic shock for diversified plants. To the extent that diversification of product mix is correlated with decentralization, using an industry level shock introduces non-random measurement error and may bias the results. Our plant-specific shock built from plant-product data addresses this concern.

Figure A1 shows the evolution of annualized export growth in the years preceding and during Great Recession using industry level data for all countries (for a total of 5,641 manufacturing sector by country cells). Exports were growing by about $13 \%$ in 2007 and $9 \%$ in 2008, and experienced a dramatic fall (-20\%) in 2009 compared to 2008. Industry sales fell even faster than exports in 2008 and 2009. In the empirical analysis, we build empirical proxies for the Great Recession by averaging 2007 and 2006 (pre-recession) and 2009 and 2008 (in-recession) levels and calculate log differences between the two sub-periods for each three-digit industry by country cell. ${ }^{17}$

Since recessions typically have a greater impact on reducing the expenditure on durable versus nondurable goods (e.g. King and Rebelo, 1999), we use as an alternative variable to capture the intensity of the Great Recession shock the average durability of the goods produced in the industry, drawn from Ramey

\footnotetext{
${ }^{15}$ We find similar results using other measures of the shock (such as industry sales derived from aggregating firm level data in ORBIS), but trade data is attractive as it has a large external component driven by demand in world markets and is available at a detailed level for every country and industry in our sample.

${ }^{16}$ All of the MOPS results are robust to using the same three-digit SIC "SHOCK" variable which is used in the cross-country WMS analysis.

${ }^{17}$ We also run robustness checks using discrete measure of $S H O C K$, in which we code an industry-country cell to be unity if exports fell over this period and zero otherwise.
} 
and Nekarda (2013). As a cross-sectional measure this is simply used at the 4-digit industry level, and is a continuous measure. ${ }^{18}$

\subsection{Descriptive Statistics}

Panel A of Table 1 contains some descriptive statistics from the WMS. The median (average) firm has 250 (574) employees and $\$ 67 \mathrm{~m}(\$ 184 \mathrm{~m})$ in sales. Firm sales declined by about $6 \%$ per year over this time period (2011-2006). Panel B has the equivalent information from MOPS. Despite being a quite different sample, the values look broadly comparable - MOPS firms are a little larger in terms of jobs (423 vs 250 at the median). MOPS plants shrank by $7 \%$ a year, similar to the WMS average. Exports fell in $51 \%$ of the industries in the sample. While the median growth rate of real exports across the whole sample is about $-0.4 \%$ and $-0.8 \%$ in the WMS and MOPS samples, respectively, the data shows considerable variation both within and across countries.

\section{Main results}

\subsection{Descriptive analysis of the main result}

Our main empirical finding is illustrated in Figure 1, in which Panel A refers to the results using the cross country WMS data, and Panel B uses the US MOPS data. Panel A shows the annualized average three-year growth rate in sales for all firms included in the WMS decentralization sample computed using data ending in the years 2011, 2010 and 2009 (hence, averaging across three different growth periods: 2011-08, 2010-07 and 2009-06). ${ }^{19}$ These are all years involving the Great Recession. ${ }^{20}$ Panel B shows sales growth for all plants in the MOPS decentralization sample (2009-06 growth rate). We exclude the 2011-08 and 2010-07 periods from the MOPS sample because the recession was over in the US in $2010 .{ }^{21}$

The sample in Figure 1 Panel A is subdivided in four categories of firms. First, we split firms according to whether they experienced a drop in exports in an industry by country cell in the main Great Recession years (the 2008 and 2009 average) compared to the latest pre-recession years (2006 and 2007 average). ${ }^{22}$ Second, we split firms by above/below the mean level of decentralization measured before the advent of the Great Recession. Not surprisingly, all our groupings of firms experienced a drop in average sales and furthermore,

\footnotetext{
${ }^{18}$ We also consider a discrete version using a dummy equal to 1 if the durability in the industry is greater than the median (and zero otherwise).

${ }^{19}$ We use long differences to smooth over some of the transitory measurement error. The results are robust to choosing alternative methods of long differencing.

${ }^{20}$ We also test the robustness of the results to dropping the 2008-2011 period, in which the Recession was starting to taper off in Europe.

${ }^{21}$ In Europe (where most of our WMS data is from) the crisis persisted due to the Eurozone currency crisis and fiscal austerity policies.

${ }^{22}$ To be precise we first divide the value of nominal exports by a country and time specific CPI. We then construct average real exports in (i) 2009 and 2008 and (ii) 2007 and 2007. We then take the log difference between these two periods.
} 
the drop in sales is clearly (and significantly) larger for firms classified in industries experiencing a negative export shock (compare the two bars on the right with the two on the left). However, within the group of firms experiencing a negative shock (those on the right of the figure), the decline in sales was significantly larger for firms that were more centralized prior to the recession. In the WMS sample, for firms in an industry-country pair hit by a greater negative shock, decentralized firms had a $8.2 \%$ fall in sales compared to about $11.8 \%$ in the centralized firms, for a difference of 3.6 percentage points which is significant at the $5 \%$ level (compared to an insignificant difference of $-0.1 \%$ in industries that did not experienced a shock). Panel B of Figure 1 performs the analogous exercise on the MOPS sample of US establishments. The difference in differences is very similar at 3.5 percentage points, also significant at the $5 \%$ level.

The performance differential between decentralized and centralized firms appears confined to the crisis period. Using the same four categories as in Figure 1, Figure 2 plots the difference in sales growth between decentralized and centralized firms (or plants), again distinguishing between those which experienced a drop in exports in an industry by country cell during the Great Recession years, including the years before and after the Great Recession. As before, the y-axis is the annualized three year growth rate in sales, with the year 2010, for example, corresponding to the 2010-07 growth rate. In both the WMS sample in Panel A and the MOPS sample in Panel B, decentralized firms (plants) and centralized firms (plants) have similar sales growth rates in the pre-recession periods (before 2008), regardless of whether they subsequently experienced a decline in exports during the Great Recession (to see this, note that the two lines in each panel do not diverge until 2007). The performance differentials between decentralized and centralized firms (plants) in industries hit by the Great Recession start to emerge in 2008, and converge in both datasets after roughly five years. ${ }^{23}$

The basic finding emerging from the raw data is that decentralization was associated with relatively better performance for firms or establishments facing the toughest environment during the crisis. Moreover, the improved performance associated with decentralization is unique to the crisis period, as these firms (plants) did not outperform their peers before the crisis, and temporary, as these firms (plants) do not appear to be systematically outperforming their centralized counterparts after the crisis. ${ }^{24}$

We now turn to more formal tests of this basic result using alternative measurement strategies and controls for many other possible confounders.

\footnotetext{
${ }^{23}$ In the US MOPS data, although not in the cross-country WMS, centralized plants in 2012 experience a more rapid recovery in the industries most affected by the Great Recession.

${ }^{24}$ One might ask why should centralized firms not systematically outperform their decentralized counterparts in "good times"? One reason related to the model of Section 2 is that although turbulence/uncertainty spikes in deep recessions (albeit to different degrees in different industries) it does not so in other times (see Bloom et al, 2016, especially Table 2). A second reason is that, although the Great Recession is a plausibly unexpected shock to which a firm's optimal decentralization did not reflect pre-recession, industry growth trends were less unusual in the pre-crisis period so firm decentralization had already been chosen endogenously to reflect these trends.
} 


\subsection{Baseline regression equation}

Our baseline specification is:

$$
\Delta \ln Y_{i j c t}=\alpha D E C_{i 0}+\beta\left(D E C_{i 0} * S H O C K_{j c}\right)+\gamma S H O C K_{j c}+\delta x_{i 0}+\theta_{c}+\phi_{j}+\tau_{t}+\varepsilon_{i j c t}
$$

where $\Delta \ln Y_{i j c t}$ is the sales growth rate: the three year annualized change in $\ln$ (real sales) for firm (or plant) $i$ in industry $j$ in country $c$ in end-year $t .^{25} D E C_{i 0}$ is firm (or plant) $i$ 's level of decentralization (measured in the initial year of 2006 for WMS and 2005 for MOPS); $S H O C K_{j k}$ is our measure of the severity of the shock of recession in the industry-country cell; $x_{i 0}$ is a set of controls also measured pre-recession (firm and plant size, survey noise and the proportion of college-educated employees); $\theta_{c}$ are country dummies, $\phi_{j}$ are industry dummies, $\tau_{t}$ are year dummies and $\varepsilon_{i c j t}$ and is an error term. Standard errors are clustered at the industry by country level, or just industry level depending on the variables used to proxy for the Great Recession and the specific sample used. When we use export growth as a measure of the shock the key hypothesis we examine is whether $\beta<0$, i.e. whether decentralized firms and plants do relatively better in bad times. When we use product durability as a measure of the magnitude of the shock the equivalent hypothesis is that $\beta>0$, as the more durable goods industries are expected to have (and do have) the largest fall in demand.

Our underlying identification assumption in equation (8) is that in the pre-Great Recession period firms were in an initial equilibrium where they had adopted their optimal degree of decentralization ( $\left.D E C_{i 0}\right)$ based on their current and expected environment. ${ }^{26}$ The $S H O C K_{j k}$ associated with the Great Recession was largely unexpected and, since organizational form is likely subject to large adjustment costs, firms could not immediately respond by changing to the optimal form of organization (i.e. becoming more decentralized) in the new environment. Thus, $D E C_{i 0}$ can be considered weakly exogenous in equation (8). We investigate the adjustment costs assumption by using repeat observations on decentralization for the same firms or plants over time. We find decentralization to be highly persistent over the time in both the WMS and MOPS samples. ${ }^{27}$ We also consider potential violations of these assumptions below (sub-section 4.4), such as the presence of other unobservables correlated with $D E C_{i 0}$ that could generate firm-level performance differentials in bad times.

\footnotetext{
${ }^{25}$ As discussed above, for the long differences we are using the three overlapping time periods for WMS, but for MOPS we can only use one of these long differences, 2009-2006.

${ }^{26}$ Formally, we do not need to assume fully optimizing behavior in the pre-period, only that $D E C_{i 0}$ is weakly exogenous.

${ }^{27}$ We estimate that the annual AR(1) coefficient on decentralization as 0.965 in MOPS and 0.707 in WMS. The true persistence parameter is likely to lie between these as MOPS estimate is likely to be an over-estimate because of recall bias and the WMS is likely to be an underestimate because of classical measurement error. See Bloom, Sadun and Van Reenen (2016) for more structural estimation of adjustment costs in WMS also showing high degrees of persistence of organizational form.
} 


\subsection{Baseline results}

Column (1) of Table 2 shows the results from estimating a simple specification including export growth as our recession shock indicator and a full set of country, year and three-digit industry dummies. A one percent increase in industry exports is associated with a significant 0.07 percentage point increase in sales growth. We also find a positive and weakly significant association between sales growth and lagged initial decentralization (in 2006). A one standard deviation increase in our decentralization index is associated with a 0.58 percentage point increase in sales growth (e.g. growth increases from say $2.0 \%$ a year to $2.6 \%$ a year). ${ }^{28}$ In column (2) we introduce an interaction term between decentralization and the export shock variable. The interaction term is negative and significant (0.042 with a standard error of 0.013$)$, which indicates that decentralized firms shrank much less than their centralized counterparts when they were hit by a negative export shock. Note that the coefficient on the linear decentralization term is insignificant when the interaction term is added to the specification, which indicates that decentralized firms did not grow significantly faster or slower in those sectors that had zero export growth.

The magnitudes of the coefficients are non-trivial. Consider a macro shock causing a $1 \%$ fall in exports. The coefficients in column (2) of Table 2 suggests that the sales of an average firm (with mean decentralization score of zero) will shrink three times as much as those of a decentralized firm (with a score one standard deviation above the mean). ${ }^{29}$ Panel $\mathrm{A}$ of Figure 3 shows the implied marginal effect of decentralization on sales growth as a function of export growth. These plots are obtained using the coefficients reported in column (2) of Table 2. According to these estimates, decentralization has a positive association with sales growth in all industries experiencing country-industry export growth below $8 \%$. This corresponds to twothirds of the WMS sample in the post recession period, but only $12 \%$ of firms in the pre-recession periods (this is shown in Panel B of Figure 3). In other words, the positive association between decentralization and firm growth appear to be contingent on the wider demand conditions in the aggregate environment facing the firm, which in turn may be one of the possible reasons for the heterogeneous levels of decentralization observed in 2006. It is important to emphasize that we are not claiming that decentralization is always the optimal form of firm organization-it is very much contingent on the different conditions that firms face..$^{30}$

The recession shock measure is industry and country specific. Therefore, in column (3) of Table 2 we include a full set of industry dummies interacted with country dummies, as well as a set of other firm controls (measured in 2006). The linear export shock is absorbed by the industry by country dummies, but

\footnotetext{
${ }^{28}$ Note that the growth rates of both firm sales and industry exports used throughout all regressions are multiplied by 100 (i.e $1 \%$ is 1 not 0.01 )

${ }^{29}$ Assuming the effects were causal for illustrative purposes, the average firm will see a drop in sales of $0.062 \%$ (the coefficient on export growth) whereas the decentralized firm will see a fall in sales of just $0.020 \%$ (0.062 minus 0.042 , the coefficient on the interaction).

${ }^{30}$ In other work done using the WMS decentralization data (Bloom, Sadun and Van Reenen, 2012) we discuss other influences on firm decentralization such as scale, human capital, complexity and culture. We exploit one source of this variation (trust) in an instrumental variable approach discussed below.
} 
we can still identify the interaction of the shock with initial firm decentralization. Even in this demanding specification, the interaction between decentralization and the shock remains negative and significant. ${ }^{31}$

A possible concern with the estimates is that the $S H O C K$ variable uses information dated over the same period as the dependent variable, which may give raise to an endogeneity bias. Consequently, we test for the robustness of the main results using as a proxy for the intensity of the Great Recession a measure of the durability of the products in the four-digit industry calculated prior to the recession. We include a full set of four-digit industry dummies to absorb the linear effects in column (4). Consistent with the earlier results, the interaction between decentralization and the $S H O C K$ is positive (since more durable industries experienced greater drops in demand during the recession) and significant. ${ }^{32}$

An alternative exogenous shifter of the shock measure to durability is to construct a Bartik style IV where we predict the change in exports from an industry-country pair. We constructed this for every HS six digit commodity in a country by interacting the lagged (i.e., built using 2006/2007 data) export share of the commodity from country $r$ to a partner country $p$ with the partner country's growth in imports (of that commodity) between 2006/07 and 2008/09 from all countries except country $r$. Summing this across all partner countries and then aggregating to the three digit industry level gives an IV for the export shock. The results from using this Bartik IV are very similar to those shown in Table $2 .{ }^{33}$

Columns (5) and (6) of Table 2 repeat the specifications of columns (3) and (4) using the MOPS sample. ${ }^{34}$ Remarkably, although drawn from a distinct dataset, a single country (US) and different survey methodology, the results in this larger sample of plants are extremely similar to the ones reported using the cross country WMS data. The coefficients on the interaction terms are of the same sign, statistically significant and of a broadly comparable magnitude.

The results discussed so far suggest the presence of a positive relationship between firm and establishment sales growth and decentralization in the industries most affected by the Great Recession. In Table 3 we explore whether this relationship persists even when we examine Total Factor Productivity (TFP), i.e. we estimate the most general econometric model of Table 2, column (3) but also control for increases in other inputs such as employment, capital and materials on the right hand side of the equation. As discussed in the introduction, some have argued that firms need to centralize during crises, so tough cost controls and efficiency-enhancing measures can be driven down throughout the company. This would imply that, although

\footnotetext{
${ }^{31}$ Other measures of the demand shock give similar qualitative results to using exports. For example, using industry output built from aggregating the ORBIS population data in the same way as exports (across the three digit industry by country cell between the 2009-08 and 2007-06 periods) generates a coefficient (standard error) on the interaction term of 0.060 (0.015).

${ }^{32}$ The specification in column (4) can be regarded as the reduced form of an IV regression where we use durability as an instrumental variable for the shock. When we use decentralization*durability to instrument for SHOCK*durability in an IV specification on the sample in column (3), we obtain a coefficient (standard error) of -0.165 (0.052) on the decentralization* SHOCKinteraction.

${ }^{33}$ For example, the IV coefficient(standard error) on the interaction of export growth and decentralization is -0.065 (0.029) using the Bartik IV. This is similar with the OLS estimate of $-0.047(0.018)$ in column (3) of Table 2 . The first stage is strong with an F-statistic of 29.5.

${ }^{34}$ Note that the linear export shock in column (5) is not absorbed by the industry fixed effects as the MOPS export shock varies at the plant level.
} 
decentralized firms (or plants) may fare better on protecting sales revenue during downturns, they will do worse in terms of productivity.

Column (1) of Table 3 reports the baseline results for sales growth on the subsample of firms with data on factor inputs, while column (2) reports the productivity results. ${ }^{35}$ Decentralization is also significantly and positively associated with an increase in TFP during a crisis. ${ }^{36}$ Column (3) uses the growth of profitability (Earnings Before Interest and Tax divided by the capital stock) as the dependent variable and also finds a negative coefficient on the interaction although it is not significant at conventional levels. Column (4) investigates whether the positive association also extends to the extensive margin of adjustment, using an exit regression. The dependent variable is a dummy taking the value of one if the firm exited to bankruptcy between 2007 and 2011 and zero otherwise (the regression is a Linear Probability Model, and the reported coefficients are multiplied by 100 for readability). This shows that more decentralized firms also had a significantly lower probability of exit in industries that were worse hit by the crisis. Columns (5) though (7) repeat the analysis using the MOPS data, and again finds a negative and significant coefficient on the interaction term between decentralization and the shock for sales, productivity and profits growth. ${ }^{37}$

\subsection{Identification and robustness}

A concern with the results is that our decentralization interaction is simply picking up longer term trends or proxying for some unobserved variable. To address these issues we took several steps.

Placebo test in a pre-crisis period First, we address the concern that the Decentralization $*$ SHOCK interaction may simply be picking up some other time-invariant industry characteristic associated with the magnitude of the recession and firm decentralization. As shown in Figure 2, the raw data suggest that the differentials in performance between decentralized and centralized firms are confined to the Great Recession. To further probe this result, we examine the relationship between sales growth and the Decentralization* $S H O C K$ interaction in a sample including years preceding the Great Recession in Table 4. Finding the same results in this period would raise the concern that the SHOCK dummy captures unobserved industry heterogeneity unrelated to the Great Recession such that decentralized firms always did better in certain sectors. Thus, we regard this as a placebo test. We look again at three year differences in growth but instead pool across the 3-year differences 2008-05, 2007-04, 2006-03 and 2005-02 to define the pre-recession growth

\footnotetext{
${ }^{35}$ The sample for the TFP regression is smaller due to missing data on some of the additional inputs needed for the production functions specification (in many countries revenues are a mandatory item on company accounts, but other inputs such as capital are not).

${ }^{36}$ The sum of the unreported coefficients on employment, capital and materials growth is about 0.9 suggesting decreasing returns to scale (and/or market power). Measurement error may also be responsible for attenuating the coefficients on factor inputs towards zero. Note that if we calculate TFP as a residual using cost shares as weights on the factor inputs and use this as the dependent variable (dropping the factor shares from the right hand side) are results are similar to those from the estimated production function.

${ }^{37}$ We have no exit data for MOPS as the survey was run in 2011 after the Great Recession, with our main results using the recall question on decentralization in 2005 .
} 
rates (in column (1) labeled ("year $<=2005$ "), and 2011-08, 2010-07 and 2009-06 (as in the earlier tables) to define the post-recession years (column (2)). Column (1) shows that the coefficient on Decentralization * SHOCK is actually positive, although insignificant, in the years preceding the Great Recession. Column (2) repeats the results of the specification of Table 2, column (3). Column (3) repeats the regression on the pooled pre-crisis and post-crisis samples of the first two columns, and includes a full set of interactions with a dummy indicator taking a value of one for all crisis years (the three year differences from 2009-06 and later) to estimate a "differences in differences in differences" specification. The coefficient on the triple interaction POST2006 * Decentralization * SHOCK interaction is negative and significant, which implies that the effect of decentralization in industries hit by the Great Recession is arising entirely from the Great Recession years. We repeated the same analysis on productivity with very similar results in the last three columns.

Observable factors correlated with decentralization We investigated whether the Decentralization* SHOCK interaction actually reflects other firm level characteristics correlated with decentralization exploiting the very rich data we have compiled. ${ }^{38}$ Specifically in Tables 5 and 6 we augment the baseline specification of column (3) in Table 2 with interactions terms between the Great Recession indicator and a series of additional firm and plant controls. First, we include interactions with human capital of the workers as well as the overall management quality of the firm (in the WMS measured as in Bloom and Van Reenen, 2007) or the plant (in the MOPS). To control for the fact that centralization might reflect firms in low profit margin market segments who always do badly in downturns (e.g. because their products are relatively homogeneous) we include interactions with pre-recession profit margins. We also tried including measures of scale (size of the plant and/or the firm), decentralization from the plant manager to production workers, technology adoption (data-driven decision making), union strength and plant manager characteristics (age, immigrant status and gender). Throughout these experiments the coefficient on our key Decentralization * SHOCK interaction remained significant. ${ }^{39}$

In the MOPS data we can implement a particularly tough test. Since we measure decentralization in multiple plants within the same firm, for multi-plant firms we are able to include an interaction between

\footnotetext{
${ }^{38}$ Ideally, we we would have an instrumental variable for decentralization, but there is no obvious candidate that credibly meets the exclusion restriction. For example, regional variation in generalized trust in the population around the firm's headquarters is strongly correlated with decentralization (see Bloom, Sadun and Van Reenen 2012). We found that firms in high trust areas outperform others in downturns-an interaction between regional trust and our export shock variable is significantly negative in the performance regressions of Table 2. This reduced form is consistent with a mechanism whereby trust causes greater firm decentralization and therefore fosters resilience in bad times. However, there may also be other mechanisms through which higher trust helps firms outperform others during downturns, so trust cannot be reliably excluded from the second stage.

${ }^{39}$ Although the additional variables were usually insignificant, there are exceptions. In Table 5, decentralization from plant manager to workers exhibits a similar pattern to our main decentralization measure of power between the central headquarters and plant manager. This suggests that decentralizing decision-making throughout the hierarchy is beneficial during times of crisis. The management interaction is also weakly significant, although in this case the coefficient is positive. In other words, well managed firms perform relatively better in good times than in bad times.
} 
the Great Recession indicator and average firm decentralization. ${ }^{40}$ This means that the coefficient on the Decentralization $*$ SHOCK interaction is identified solely off differences in decentralization across plants within the same firm. Remarkably, the results remain significant even in the presence of the firm level of decentralization and its interaction with export growth (coefficient of -0.023 and standard error of 0.010 ).

A further concern is that the $S H O C K$ measure could be reflecting other industry characteristics rather than the demand fall. In Appendix Table A3 we show that our key interaction is robust to including interactions of decentralization with a number of other industry characteristics such as asset tangibility, inventories, dependency on external finance and labor costs.

Validity of exports as a shock measure We have argued that trade changes are an attractive indicator of the Great Recession shock, as they are more likely to reflect what is happening to demand in world markets than being a reflection of country and industry specific supply factors. Furthermore, we have also shown above that our results are robust to alternative indicators of the shock such as the industry-specific durability measure, a Bartik style IV for exports or using industry output instead of exports. As a further check we estimated our models separately for exporting establishments vs. non-exporting establishments using the MOPS data (export data is not an item required in the company accounts data). As expected, the results are driven by the exporting plants who are most directly exposed to trade shocks. ${ }^{41}$

Asymmetries We investigated whether a negative shock differed from a positive shock by allowing different coefficients on positive than negative shocks (defined either as positive export growth or export growth above/below the median value). In all cases we found we could not reject symmetry. This is unsurprising since in the Great Recession period most firms were experiencing various degrees of a negative shock.

\subsection{The role of co-ordination costs}

When there are large externalities between different plants belonging to the same firm, decentralization is likely to be more costly (Alonso et al, 2008). For example, coordinating prices and product decisions from the central headquarters is important if the sales of one plant's products cannibalize those of other plants. This may be less plausible in the case of WMS since these firms are medium sized (typically containing only two plants and 233 employees). Nonetheless, to examine whether our results may reflect the importance of differences in coordination in bad times, in Tables 7 and 8 we included interactions with many measurable characteristics reflecting environments where coordination costs should be more important. These included firm and/or plant size and whether a firm was multi-plant (so more need for coordination) and, if so,

\footnotetext{
${ }^{40}$ Bloom, Brynjolfsson, Foster, Jarmin, Patnaik, Saporta-Eksten and Van Reenen (2016) show there is considerable variation in organization within firms across plants at a point in time.

${ }^{41}$ For example, using the baseline MOPS specification in Table 2 column (5) we estimate a coefficient(standard error) of $-0.036(0.012)$ on the Decentralization ${ }^{*} S H O C K$ variable for the exporters (4,200 observations) and $-0.011(0.012)$ for the nonexporters. These results are shown in Appendix Table A7.
} 
whether these plants are located in different countries or different states. Similarly, we looked at whether a firm was producing goods across multiple sectors ("diversification" dummy) or whether it was part of a foreign multinational enterprise. We also considered the degree of outsourcing (a direct question in WMS) and alternatively as measured by the ratio of intermediate goods inputs to total sales.

In all cases the main interaction between decentralization and export growth remained significant, and in only one of the 16 cases was one of the other interactions significant at the $5 \%$ level. ${ }^{42}$ Although coordination costs matter in general for centralization, they do not seem to account for the better performance of decentralized firms during downturns.

\section{Extensions: Understanding the Mechanism}

\subsection{Turbulence: Product churn and stock market volatility}

Our empirical findings strongly suggest that decentralization becomes more valuable in bad times. The simple model in Section 2 suggested that one reason for this was that negative shocks may be associated with greater turbulence (a higher $u$ ), which increase the benefits of local information (see equation (2)). We now turn to study whether there is any direct evidence to support this idea.

Product Churn Our main measure of turbulence is changes in product churn in recession versus non recession years as a proxy. Product churn is measured using data from the US Census of Manufactures (CM). The CM, which is conducted in years ending in 2 and 7 , asks manufacturing plants to list the value of annual shipments by 10-digit product code. Plants receive a list of all the product codes typically produced in their industry, along with corresponding descriptions of each code. Plants which produce products not listed on the form are instructed to write in the appropriate product code. ${ }^{43}$ We then measure the amount of product churn at the plant level as the number of products added or dropped between the previous Census and the current Census, divided by the average number of products produced in both Censuses. That is, product churn for establishment $i$ in year $t$ is defined as:

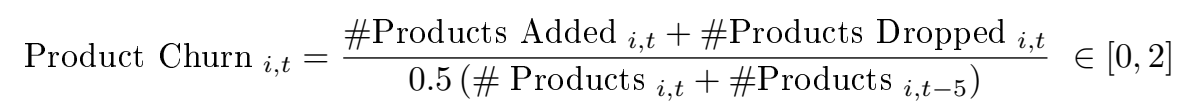

Our measure of industry product churn is the average plant level product churn amongst all plants within an industry (three digit US SIC-1987) which produce at least 3 products. We restrict attention to plants

\footnotetext{
${ }^{42}$ This is the materials share in column (9) in the WMS regressions of Table 7. Two other interactions with decentralization-the number of plants and the number of manufacturing industries in columns (4) and (8) of the MOPS regressions in Table 8-are significant at the $10 \%$ level. This could be taken as (weak) evidence that firms with more co-ordination issues with supply chains, scale or industry diversification do worse during downturns when presumably lack of co-ordination becomes more costly.

${ }^{43}$ The ASM also has a 10-digit product trailer, but the question is formulated in a way that results in less detailed responses than the 5-yearly CMF question, so we use the CMF to measure churn.
} 
with at least 3 products in order to reduce measurement error from product code misreporting. ${ }^{44}$ Finally, in order to measure the change in product churn by industry during the Great Recession, we calculate the change in product churn from 2007 to 2012 as industry-level product churn in 2012 minus industry-level product churn in 2007 (constructed from the 2007 and 2002 Censuses). ${ }^{45}$

Before examining the relationship between sales growth, decentralization and turbulence (as measured by product churn), we first examined whether decentralization really was greater in industries where turbulence was higher. Figure A2 shows that this is indeed the case: plants in the top quintile of product churn industries had a decentralization index about 0.2 of a standard deviation higher than those in the bottom quintile. More formally, Table A4 finds a positive and significant relationship between decentralization (the dependent variable) and product churn, particularly for decentralization of decisions regarding product introduction and sales and marketing, as the theory would suggest. Furthermore, we checked whether product churn had indeed increased more in industries that experienced a larger drop in exports during the Great Recession. This is also the case in the data, as shown in Figure A3.

To investigate the empirical validity of the turbulence-based theoretical mechanism, we extend our basic equation (8) to include both the change in $C H U R N$ and also its interaction with decentralization

$$
\begin{aligned}
\Delta \ln Y_{i j}= & \alpha D E C_{i 0}+\beta\left(D E C_{i 0} * S H O C K_{j}\right)+\gamma S H O C K_{j} \\
& +\eta \Delta C H U R N_{j}+\mu\left(D E C_{i 0} * \Delta C H U R N_{j}\right)+\delta x_{i 0}+\phi_{j}+\tau_{t}+\varepsilon_{i j}
\end{aligned}
$$

where $\triangle C H U R N_{j}$ is the change in churn in industry $j$ (since we estimate this regression model only in the US MOPS sample we omit the country sub-script). According to the model $\mu>0$, since churn increases the value of decentralization. Moreover, to the extent that our export shock variable is proxying for rising turbulence during recessions, we would also expect $\beta$ to drop in magnitude in equation (10) compared to equation (8).

Table 9 shows the results of this exercise. ${ }^{46}$ In column (1) we estimate the specification in column (4) of Table 2 for the subset of establishments for which an industry level measure of product churn could be built. This has similar results to the overall sample, i.e. the coefficient on the interaction $D E C_{i 0} *$ $S H O C K_{j}$ is negative and statistically significant. Column (2) includes the $D E C_{i o} * \triangle C H U R N_{j}$ interaction

\footnotetext{
${ }^{44}$ Establishments which produce the same portfolio of products in consecutive Censuses but misreport a product code in one year will be incorrectly measured as having switched products. Product code misreporting is particularly problematic for establishments with 1 or 2 products, for whom a single reporting mistake would result in very high measured product churn. Our results are robust to using industries with plants with a lower cut-off of 2 or more products or a higher cut-off of 5 or more products.

${ }^{45}$ Note that the measure is based on plants who survived between Census years. We also constructed an alternative measure that included plants which died and entered between Census years in the construction of equation (9). This broader measure led to similar results.

${ }^{46}$ Since we are measuring churn 2012-2007 (our Census of Manufactures years) we use as our dependent variable the change in $\ln$ (sales) between 2007 and 2012 which is why the sample is slightly smaller.
} 
instead of the $D E C_{i 0} * S H O C K_{j}$ interaction. In line with the model's prediction, the coefficient on the interaction with changes in product churn is positive and significant, i.e. sales growth appears to have a positive association with decentralization in industries that experienced a greater increase in turbulence, as proxied by product churn. Column (3) includes both interactions. The coefficient on the interaction between decentralization and product churn remains positive and significant, while the coefficient on the interaction between decentralization and growth in industry exports drops by a quarter in magnitude compared to column (1) and is statistically insignificant. Columns (4) to (6) repeat the same specifications, this time using durability as an alternative industry level proxy for the Great Recession. The coefficient on the interaction between decentralization and product churn is positive and significant, and its inclusion again reduces the magnitude of the coefficient on the interaction between decentralization and durability to insignificance.

Stock Market volatility We also use as an alternative proxy for the increase in market turbulence a measure derived from the uncertainty literature. We measure the standard deviation in monthly firm-level stock market returns in an industry by year cell over the population of publicly listed firms in each country. The stock returns measure of uncertainty is the most standard firm-level measure and similar to those used by Leahy and Whited (1996) for example. In a stochastic volatility model based on Dixit and Pindyck (1994) the variance of stock returns will be a good predictor of the underlying level of uncertainty. These measures are then used in changes as an alternative proxy for the increase in turbulence. In the US we pool at the three digit SIC level as there are about 2,000 publicly listed firms. In the other OECD countries there are fewer publicly listed firms so we construct the measure at the SIC 2 digit level. An advantage of this measure is that it is available for the WMS as well as MOPS, but a disadvantage is that it is constructed only from firms listed on the stock market (in the same industry).

Table 10 shows the results. In column (1) we reproduce the specification in column (2) of Table $2 .{ }^{47}$ In column (2) we use the interaction between decentralization and the change in the standard deviation of stock market returns instead of our usual interaction. As expected from the theory, the coefficient is positive and significant suggesting that decentralized firms outperform their centralized counterparts in industries where stock market volatility has increased by most. In column (3) we include both interactions. The stock market volatility interaction remains positive and significant whereas the coefficient on the export growth interaction falls by a third in magnitude and is now only significant at the $10 \%$ level. The next three columns reproduce the same specifications using the MOPS data showing a qualitatively similar pattern.

Summary on Turbulence Taking Tables 9 and 10 together, it appears that decentralized firms did relatively better in industries where turbulence increased. At least part of the reason why decentralized

\footnotetext{
${ }^{47}$ The only difference is that we are using two-digit dummies instead of three-digit dummies to match the level of aggregation for the stock market volatility measures.
} 
firms do better in bad times appears to be because the industries worse hit by the Great Recession were also those where turbulence also increased, consistent with our simple model.

\subsection{Types of decentralization}

As a related experiment to shed light on the model we looked at the different sub-questions which form the overall decentralization index, as shown in Table 11. Since the Great Recession was associated with a decrease in output demand, we would expect that decentralization capturing managerial discretion over outputs (sales and new products) would be more important than delegation over inputs (like labor and capital). We start in column (1) by showing the baseline result of Table 2, column (3). In columns (2) and (3) we repeat the estimation using as the decentralization index a z-scored average of the two questions capturing plant manager decentralization for hiring and investment decisions in column (2), and for sales and marketing and product introduction in column (3). In columns (4) to (6) we repeat the same exercise for the U.S. MOPS sample. ${ }^{48}$

In both cases, the positive effect of decentralization in a crisis is primarily driven by the output related questions. This finding provides additional insight on the possible mechanism through which decentralization may positively affect performance during a downturn, namely the ability to better adapt to more turbulent demand conditions. ${ }^{49}$

One concern with these findings is the belief that in practice plant managers do not have meaningful autonomy in decisions regarding sales and marketing and product introduction, and that these decisions are typically undertaken in the marketing department of firm headquarters. It is worth recalling that while this may be the case in business-to-consumer firms which sell their goods to households directly or through retail establishments, it is less obvious in business-to-business firms which sell their manufacturing output to other firms. The latter scenario encompasses a significant share of US and EU manufacturing activity. ${ }^{50}$ Moreover, our firms are not so large-a median of 250 employees in WMS and 423 in MOPS so few of them are likely to have standalone marketing divisions.

\subsection{Do bad times reduce the costs of decentralization?}

Our theory suggested that congruence could fall in recessions (the "centralist" view) leading to an increase in the value of centralization. Our main result rejected this as decentralized firms performed better in bad

\footnotetext{
${ }^{48}$ In the U.S. sample we have 3 questions capturing plant manager decentralization for hiring and investment decisions in column (5) and 3 capturing plant manager decentralization for sales and marketing and product introduction in column (6).

${ }^{49}$ Consistent with the previous sub-section Appendix Table A5 shows that the positive interaction between decentralization and product churn is driven primarily by the sales and marketing and product introduction questions.

${ }^{50}$ According the Bureau of Economic Analysis, over 90 percent of US manufacturing output goes to the manufacturing sector, which will be primarily business-to-business transactions: https://www.bea.gov/industry/xls/ioannual/IOMake_Before_Redefinitions_1997-2015_Sector.xlsx. This will be similar in Europe, which like the US has a higherend manufacturing sector focused more at business consumers (Chinese manufacturing output, in contrast, is more consumer focused).
} 
times. There may, however, be alternative rationalizations of these results. Imagine, for example, that bad times reduce the costs of decentralization because the plant manager fears that performing the non-profit maximizing action might cause the firm to go bankrupt, and this will be more costly to the manager than CEO, as he will take a larger hit to their income (e.g. through longer unemployment). To test this idea we examine environments where the firm-specific risk of bankruptcy rose rapidly in the Great Recession. We constructed several indicators of increased bankruptcy risk. In particular, we used the measures of exogenous increases in exposure to financial crisis exploited by Chodorow-Reich (2014) such as exposure to mortgage-backed securities (affected by the sub-prime crisis) and a firm's pre-existing relationship with Lehman Brothers or similar "at-risk" banks. These are pre-Great Recession conditions relating to the supply of finance rather than product demand. We also used more conventional measures such as leverage ratios.

We found that these measures do predict negative performance in sales and other outcomes (see Appendix Table A6), as in Chodorow-Reich (2014). However, in no case did including these bankruptcy risk variables (and their interactions with $S H O C K$ or other covariates) materially alter the coefficient on the key interaction of Decentralization $* S H O C K$ when included in equation (8). ${ }^{51}$ This led us to conclude that the crisis was not leading to greater decentralization by fostering greater alignment between the central headquarters and plant manager.

\subsection{Changes in decentralization over time}

Recall that our identification assumption is that pre-recession decentralization is weakly exogenous and that there are some adjustment costs which mean that after the Great Recession shock firms do not immediately adopt the new optimal (more decentralized) organizational form. A corollary of our theory, however, is that firms will start moving to a more decentralized form (to the extent that they believe the shock is likely to be long-lasting). Hence, we should expect to see some increase in decentralization for firms and establishments more exposed to the shock. Table A 8 examines this by using the change in decentralization as a dependent variable. This is a demanding specification, especially for WMS where the panel element of decentralization is limited (we have data in 2009 and 2010 for a sub-sample of the 2006 wave). Nevertheless, in both WMS and MOPS we do see a significant and positive relationship between the size of the negative shock and decentralization.

\footnotetext{
${ }^{51}$ The coefficients on the Lehman Brothers variable cannot be reported due to Census disclosure rules. Note, because of the need to match our data with the Chodorow-Reich (2014) data our sample size falls to 2,000 observations, so many of our results are not statistically significant, but point estimates are similar and unaffected by the controls for financial conditions.
} 


\section{Conclusion}

When does decentralizing power from the central headquarters to plant managers increase firm growth? We formalized a simple model where the CEO considers decentralizing product-related decisions to the plant manager. The increased turbulence that comes with bad times has theoretically ambiguous effects on firm performance. On the one hand, it may reduce the congruence between the CEO and the plant manager, thus increasing the benefit of centralization. On the other hand, it makes the plant manager's local information more valuable, and so implies that decentralized firms will perform relatively better in unexpected downturns.

To empirically investigate these issues we collected new data on a panel of firms in 10 OECD countries (WMS), and plants in the US (MOPS) and exploited the negative shock of the Great Recession which reduced demand across industries and countries in heterogeneous ways. Using our pre-recession data on decentralization we find that negative shocks hurt growth in centralized firms and establishments significantly more than in their decentralized counterparts. This is true whether we use export shocks which vary at the industry by country (WMS) or establishment (MOPS) level, or exogenous predictors of these negative shocks like product durability. Further, as the localist model suggests, this effect is driven by the industries which experienced a greater increase in the turbulence (as measured by product churn and stock market volatility) that accompanied the crisis.

As discussed above, the effects are not trivial in size at the micro level, but we can also perform some very rough calculations at the macro level (see Appendix B and Table A9 for details). We estimate how much of the post crisis differences in GDP growth performance across countries are related to the different levels of pre-crisis decentralization. Under this view, the fact that the US had relatively more decentralized (and therefore flexible) firms meant that it could weather the global economic storm better than many more centralized countries. Assuming the financial crisis was a common cross country negative shock, we can trace out the implied post shock growth performance depending on each nation's average decentralization. We calculate that greater decentralization in the US could account for about $15 \%$ of the US 's superior GDP growth post 2012-2007 compared to the other OECD countries in our sample.

We see our paper as a first attempt to unravel the relationship between growth and the internal organization of firms using micro data with observable measures of decentralization. There are many directions to take the research. First, we need to look at the ways in which, in the longer-run, firms change their organizational forms. For example, as the effects of the Great Recession recede, how will the growth effects and degree of decentralization change? Second, we would like to go deeper into the relation between the debt structure of companies (and so their bankruptcy risk) and the incentives for firms to change. Finally, it would be valuable to examine the macro-economic implications of our modeling framework in more detail. Do the effects we identify matter in terms of thinking about business cycles and how economies and companies can be resilient to these adverse events? 


\section{References}

Acemoglu, D. P. Aghion, C. Lelarge, J. Van Reenen and F. Zilibotti (2007), "Technology, Information, and the Decentralization of the Firm", Quarterly Journal of Economics, 122 (4), 1759-1799.

Aghion, P. and J.Tirole (1997), "Formal and Real Authority in Organizations", Journal of Political Economy, 105(1) 1-29.

Aghion, P., N. Bloom and J. Van Reenen (2014) "Incomplete contracts and the internal organization of firms", Journal of Law, Economics and Organization 30(1), 37-64.

Aghion, P; P. Askenazy, N. Berman, G. Cette and L. Eymard (2012) "Credit Constraints and the Cyclicality of R\&D Investment: Evidence from France", Journal of the European Economic Association, 10, 1001-1024.

Alfaro, L. and M. Chen (2012) "Surviving the Global Financial Crisis: Foreign Ownership and Establishment Performance." American Economic Journal: Economic Policy 4(3), 30-55

Alonso, R., W. Dessein and N. Matouschek (2008) "When Does Coordination Require Centralization?" American Economic Review, 98(1): 145-79.

Bernard, A. and O. Toshihiro (2015) "Product switching and the business cycle", CEP Discussion Paper 1432 .

Bloom, N. and J. Van Reenen (2007), "Measuring and Explaining Management Practices Across Firms and Countries", Quarterly Journal of Economics, 122(4), 1341-1408.

Bloom, N., R. Sadun, R and J. Van Reenen (2012) "The Organization of Firms Across Countries", Quarterly Journal of Economics, 127(4), 1663-1705.

Bloom, N., R. Sadun and J. Van Reenen (2016) "Management as a Technology", NBER Working Paper 22327 .

Bloom, N., M. Floetotto, N. Jaimovich, I. Saporta-Eksten and S. Terry (2016) "Really Uncertain Business Cycles", Stanford mimeo

Bloom, N., E. Brynjolfsson, L. Foster, R. Jarmin, M. P., I. Saporta-Eksten and J. Van Reenen (2017) "What drives Management Practices?" Center for Economic Performance Discussion Paper 1470

Blundell, R., D.A. Green and W. Jin (2016), "The UK Wage Premium Puzzle: How did a large increase in university graduates leave the education premium unchanged?", Institute for Fiscal Studies Working Paper $16 / 01$.

Bradley W., H. Aldrich, D. A. Shepherd and J. Wiklund (2011), "Resources, Environmental Change, and Survival: Asymmetric Paths of Young Independent and Subsidiary Organizations", Strategic Management Journal, 32: 486-509.

Bresnahan, T., E. Brynjolfsson, and L. Hitt, (2002) "Information Technology, Workplace Organization, and the Demand for Skilled Labor: Firm-Level Evidence," Quarterly Journal of Economics, 117 (1), 339-376.

Brynjolfsson, E. and K. McElheran (2016) "The rapid rise of data-driven decision making" American Economic Review: Papers and Proceedings, 106 (5), 133-139.

Broda, C. and D. Weinstein (2010) "Product creation and destruction: Evidence and price implications" American Economic Review, 100, 691-723. 
Caroli, E., and J. Van Reenen (2001) "Skill Biased Organizational Change", Quarterly Journal of Economics, 116(4), 1449-1492.

Chodorow-Reich, G. (2014) "The employment effects of credit market disruptions: Firm-level evidence from the 2008-09 financial crisis" Quarterly Journal of Economics, 129(1), 1-59.

D'Aurizio, L., T. Oliviero and L. Romano (2015) "Family firms, soft information and bank lending in a financial crisis" Journal of Corporate Finance 33(3) 279-292

Dessein, W. (2002) "Authority and Communication in Organizations", Review of Economic Studies, 69 (4), 811.

Dixit, A. and R. Pindyck (1994) Investment under uncertainty, Princeton: Princeton University Press.

Garicano, L. and L. Rayo (2016) "Why Organizations Fail: Models and Cases" Journal of Economic Literature, 54 (1), 137-192.

Gibbons, R., N. Matouschek and J. Roberts (2013) "Decisions in Organizations" Chapter 10 373- 431 in R. Gibbons and J. Roberts (eds) Handbook of Organizational Economics.

Gibbons, R. and J. Roberts (2013) Handbook of Organizational Economics. Princeton: Princeton University Press

Grossman, S., and O. Hart (1986) "The Costs and Benefits of Ownership: A Theory of Vertical and Lateral Integration," Journal of Political Economy, 691-719.

Guadalupe, M. and J. Wulf (2010) "The Flattening Firm and Product Market Competition: The Effect of Trade Liberalization on Corporate Hierarchies," American Economic Journal: Applied Economics, 2 (4), $105-127$.

Hart, O., and J. Moore (2005) "On the Design of Hierarchies: Coordination versus Specialization," Journal of Political Economy, 113(4) 675-702.

King, R.G. and S.T. Rebelo (1999) "Resuscitating Real Business Cycles", in Handbook of Macroeconomics, John B. Taylor and Michael Woodford (eds.), Elsevier.

Lafontaine, F. and M. Slade (2007) "Vertical Integration and Firm boundaries", Journal of Economic Literature, $45(3)$ 629-685

Lange, O. (1936) "On the Economic Theory of Socialism" Review of Economic Studies, 4(1) 53-71.

Leahy, J. and T. Whited (1996), "The Effects of Uncertainty on Investment: Some Stylized Facts", Journal of Money Credit and Banking, 28, 64-83.

Pierce, J. and P. Schott (2009) "A Concordance between Ten-Digit U.S. Harmonized System Codes and SIC/NAICS Product Classes and Industries", Mimeo, Yale University.

Pierce, J. and P. Schott (2010) "Concording US Harmonized System Codes Over Time", Mimeo, Yale University.

Prendergast, C. (2002) "The Tenuous Trade-Off between Risk and Incentives" Journal of Political Economy, 110(5) 1071-1102

Ramey, V. and C. Nekarda (2013) "The cyclical behavior of the price-cost markup" UC San Diego mimeo.

Rajan, R.G. and J. Wulf (2006) "The flattening firm: Evidence from panel data on the changing nature of corporate hierarchies," Review of Economics and Statistics, 88 (4), 759-773.

Von Hayek, F. (1945) "The Use of Knowledge in Society" American Economic Review, 35(4) 519-53. 
Figure 1: Changes in Sales by Shock and Decentralization Panel A - WMS Data

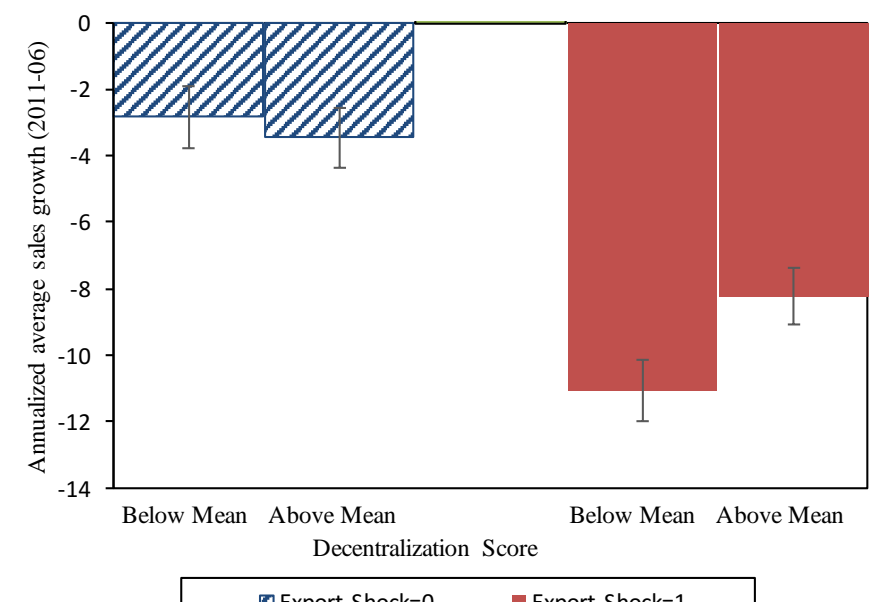

Panel B - MOPS Data

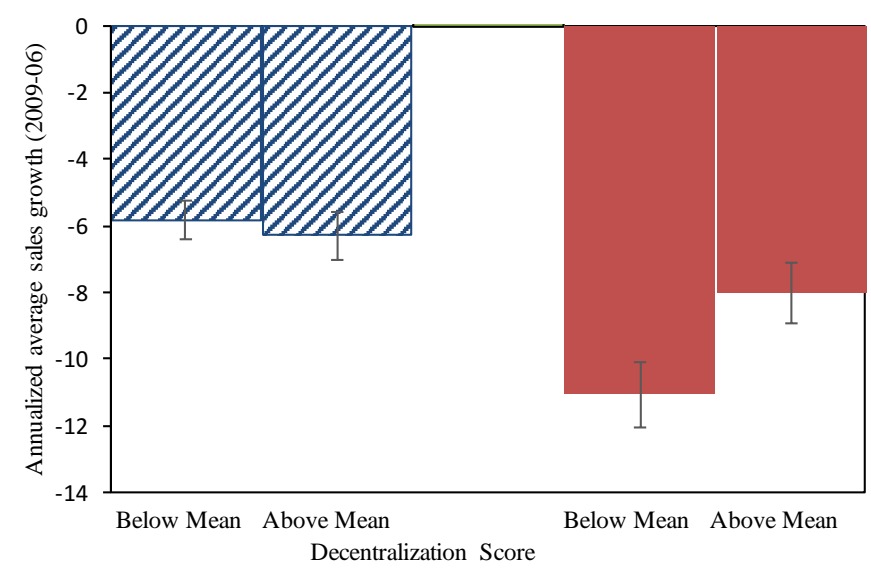

$\square$ Export Shock $=0$

Export Shock=1

Notes: Panel A uses WMS firm data from 10 OECD countries. In Panel A the bars plot annualized average of three-year firm-level change in $\ln$ (sales) over 2011-08, 2010-07 and 2009-06. 95\% confidence interval bands reported. "Export Shock" is whether firms were in a country-industry cell that experienced a drop in the average level of exports in 2008 and 2009 (the main Great Recession years) compared to the average level in 2006 and 2007 (the latest pre-Recession years). Right hand side bars are industry-country cells were the shock was worst. Firms are split into whether they are decentralized (above the overall mean of decentralization in 2006) or centralized. Sample size in each bar in Panel A (from left to right) is (1) 695 observation over 296 firms; (2) 863 obs, 352 firms; (3) 736 obs, 316 firms; (4) 857 obs, 367 firms. Panel B is the same as Panel A except we just use one 2009-06 long difference for plant sales growth and decentralization dated in 2005. The sample in Panel B includes 8,774 US plants in 3,147 firms. 
Figure 2: Changes in Sales by Shock, Difference between Decentralized minus Centralized Firms Panel A - WMS data

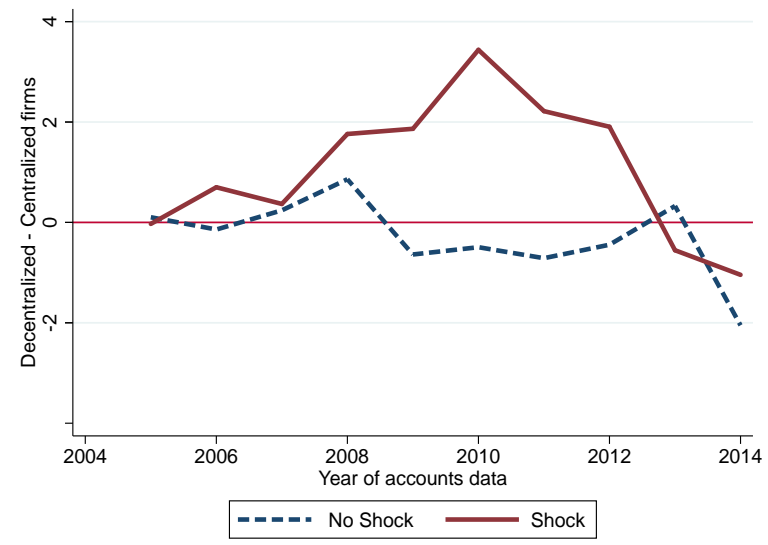

Panel B - MOPS data

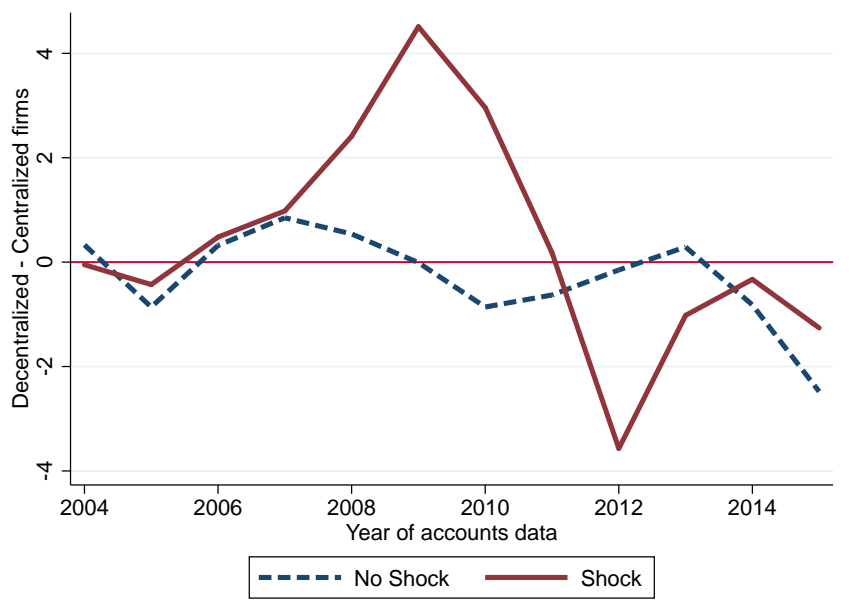

Notes: Panel A uses WMS firm data from 10 OECD countries. In Panel A, the lines plot annualized average three-year firmlevel change in $\ln$ (sales) for decentralized firms minus annualized average three-year change in $\ln ($ sales) for centralized firms, distinguishing between firms that experienced an export shock during the Great Recessions, versus those that did not. Growth rates are shown for each year starting with the 2005-02 growth rate through the 2014-11 growth rate. "Shock" is whether firms were in a country-industry cell that experienced a drop in exports in 2008 and 2009 (the main Great Recession years) compared to 2006 and 2007 (the latest pre-Recession years). Panel B uses MOPS plant data from the U.S. In Panel B, the lines plot annualized average three-year plant-level change in $\ln$ (sales) for decentralized plants minus annualized average three-year change in $\ln$ (sales) for centralized plants, distinguishing between plants that experienced an export shock during the Great Recessions, versus those that did not. Growth rates are shown for each year starting with the 2004-01 growth rate through the 2015-12 growth rate. "Shock" is whether plants produced products (measured before the crisis) which on average experienced a drop in exports in 2008 and 2009 (the main Great Recession years) compared to 2006 and 2007 (the latest pre-Recession years). 
Figure 3: Effect of Increase in Decentralization on Sales Growth

Panel A

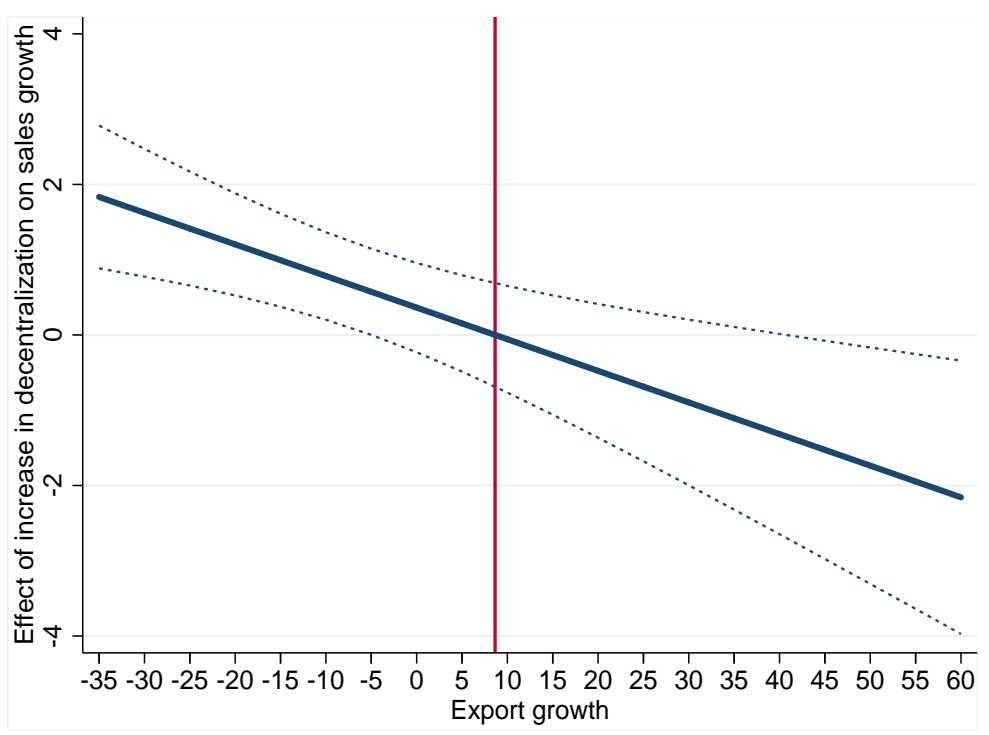

\section{Panel B}

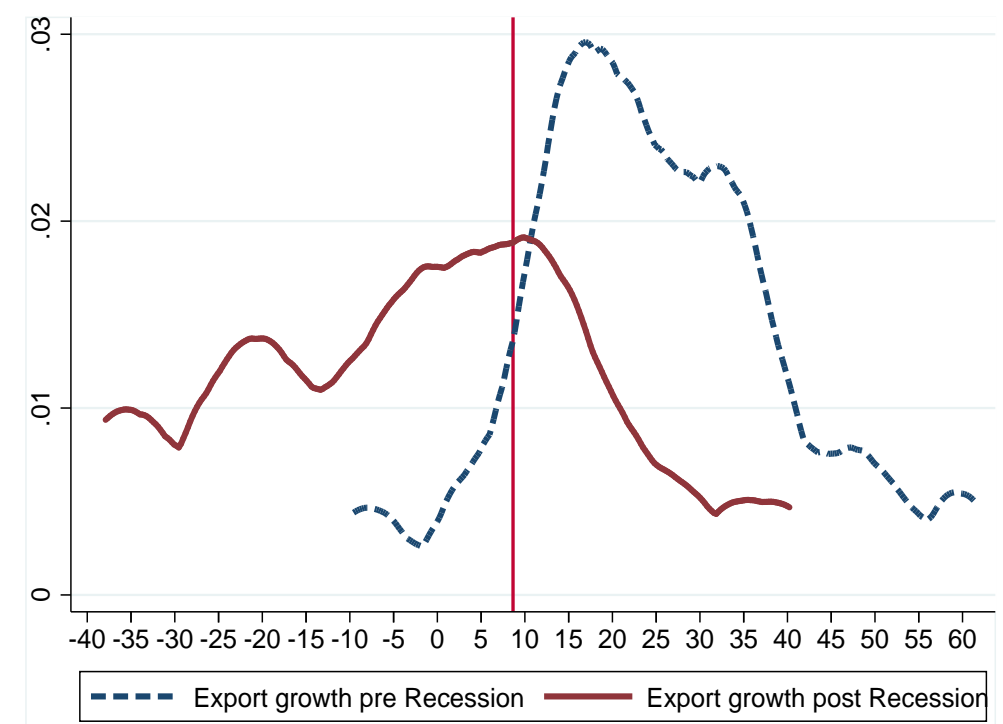

Notes: WMS Data. Panel A plots the implied marginal effect of decentralization on firm sales growth using the coefficients in Table 2 column (2) as a function of the shock (export growth in cell). Panel B shows the distribution of firms in industry-country cells with different levels in cell). Panel B shows the distribution of firms in industry-country cells with different levels of export growth before and after the Great Recession. 


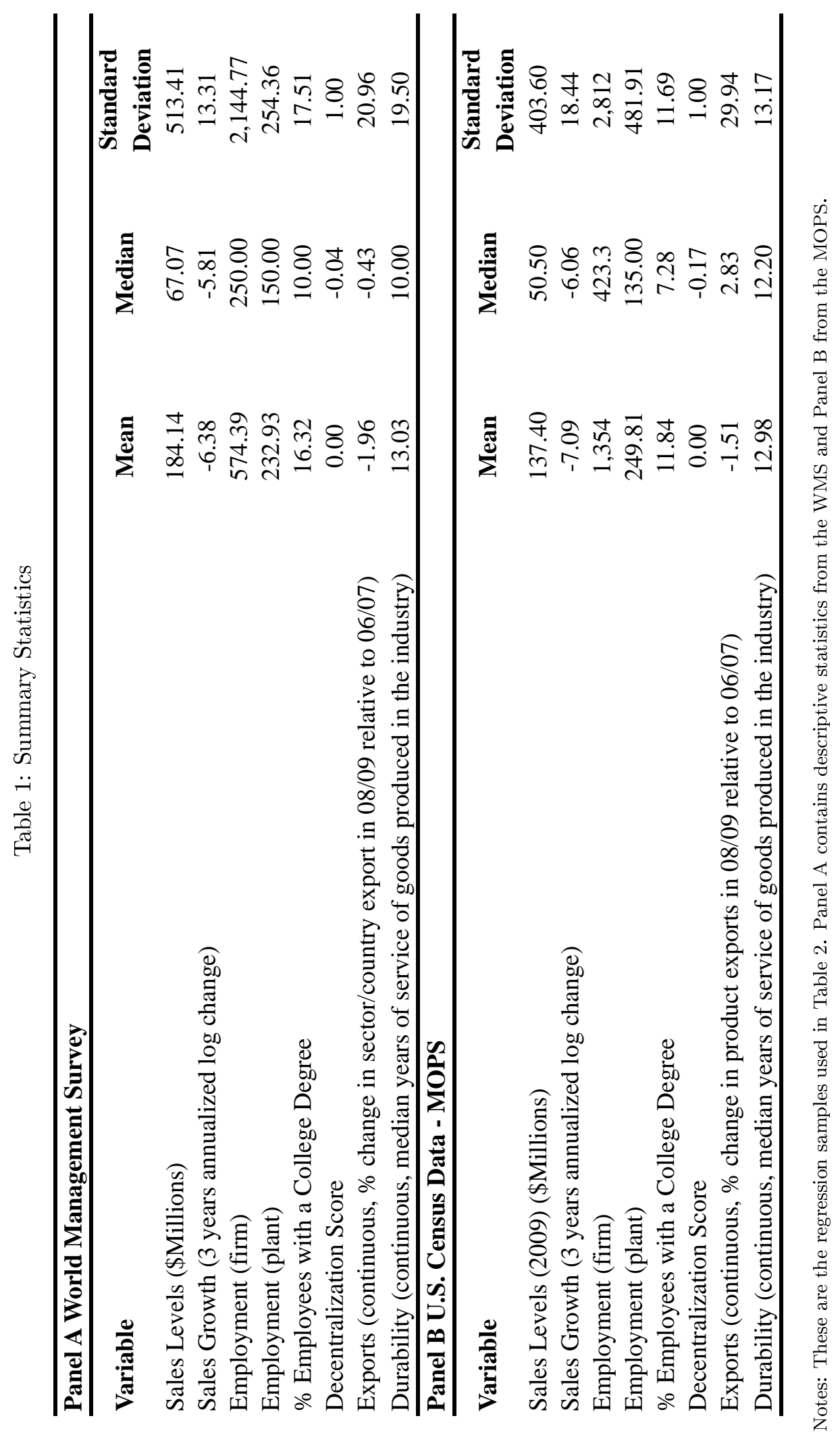




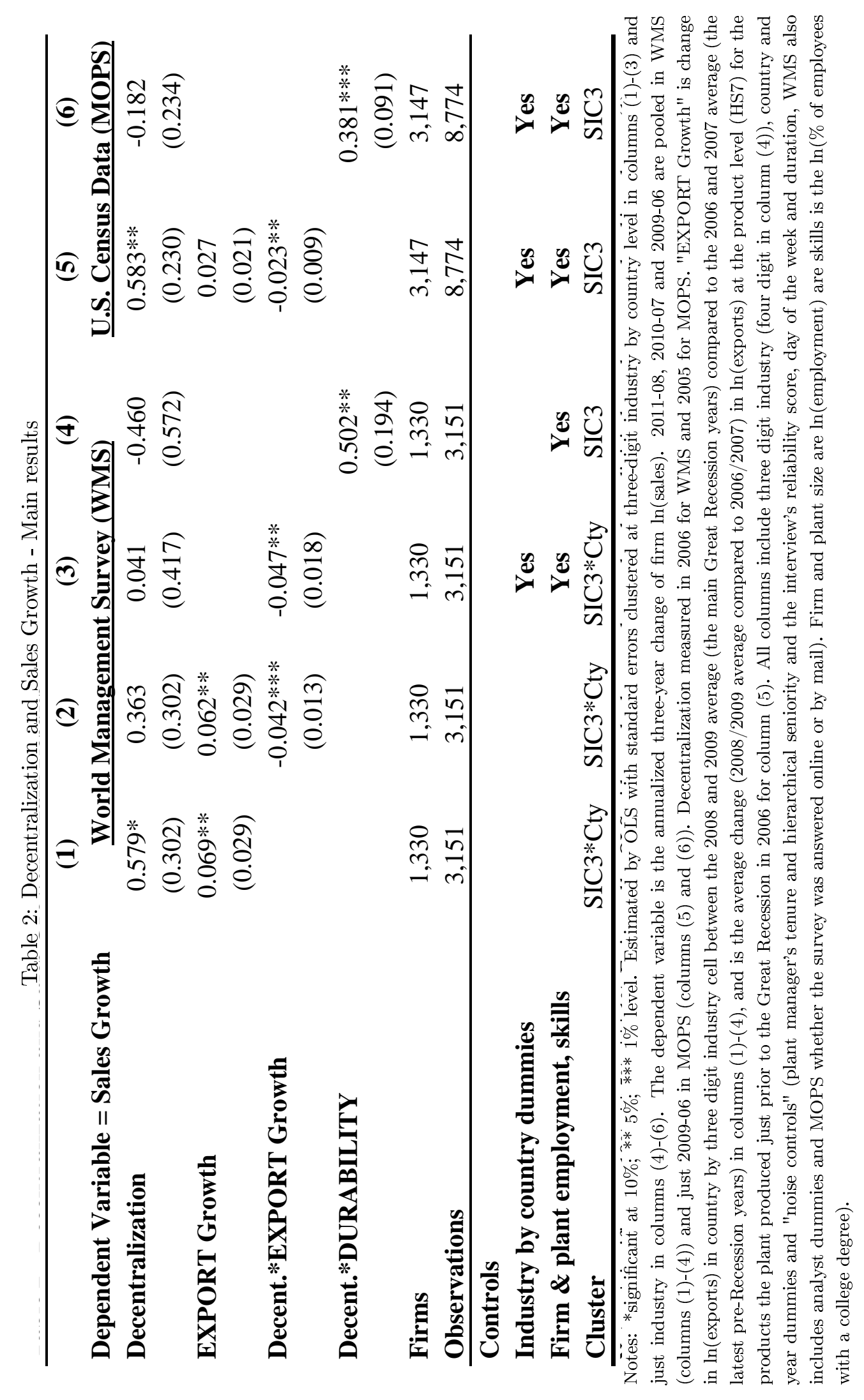




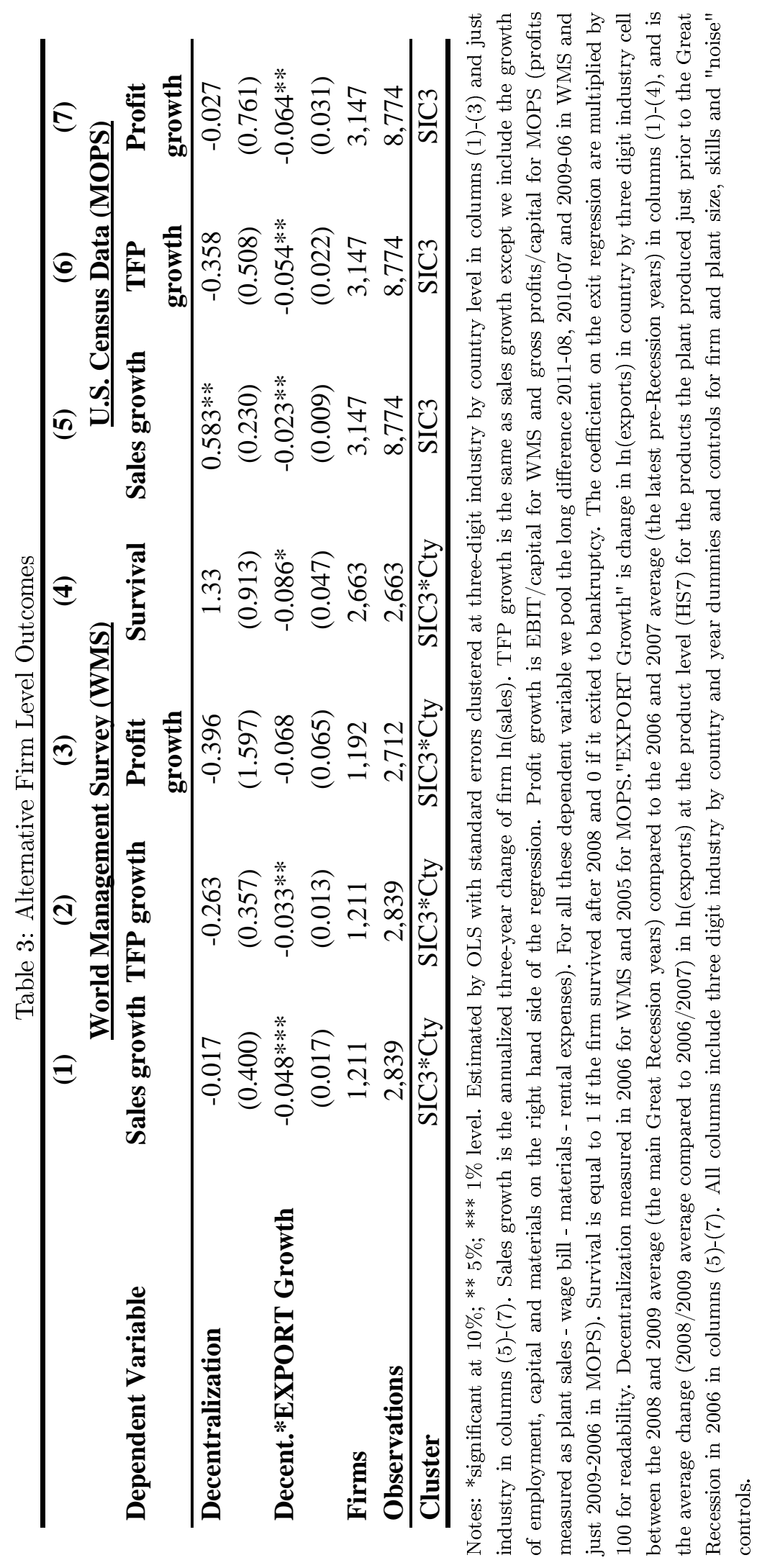




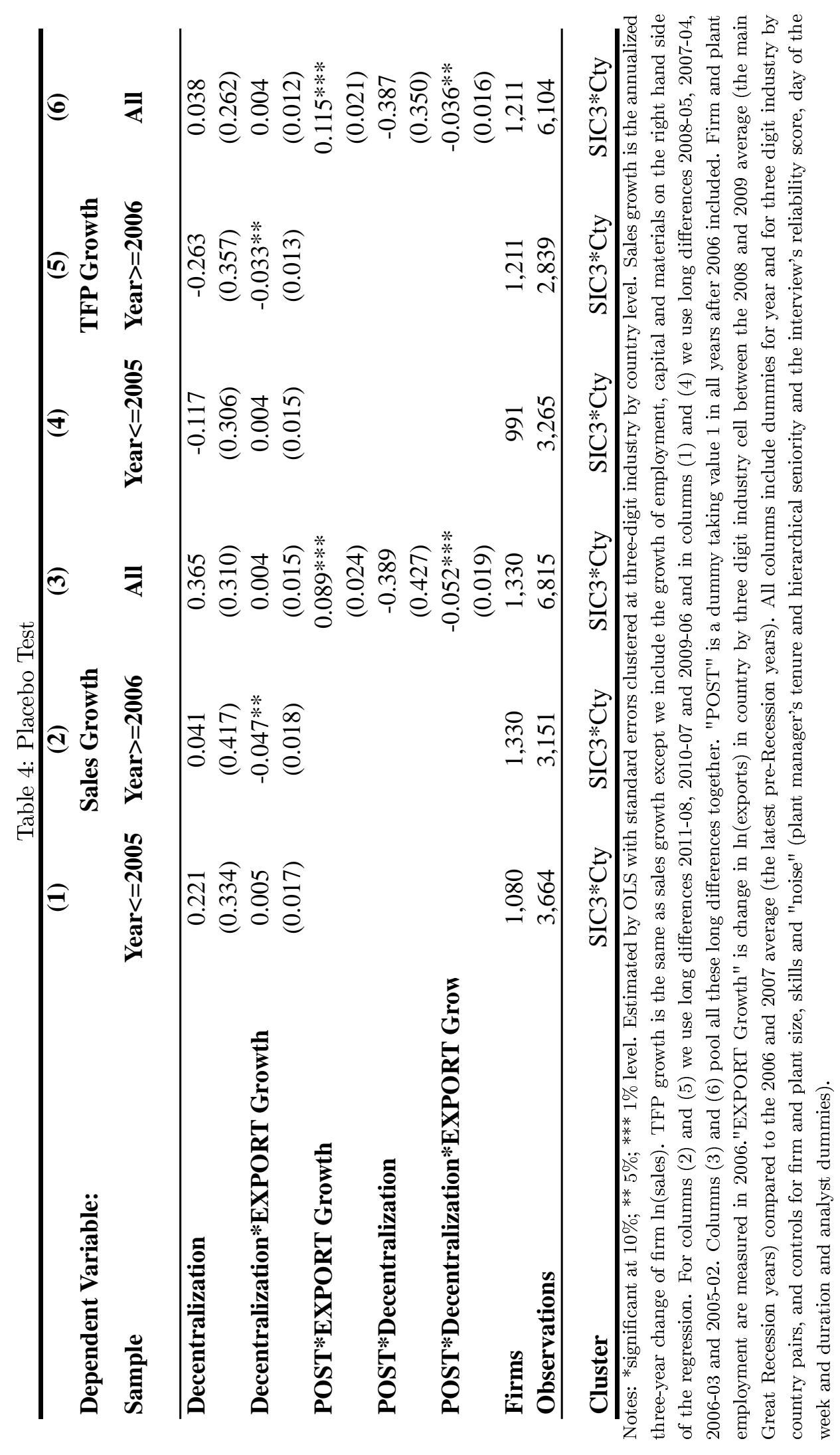



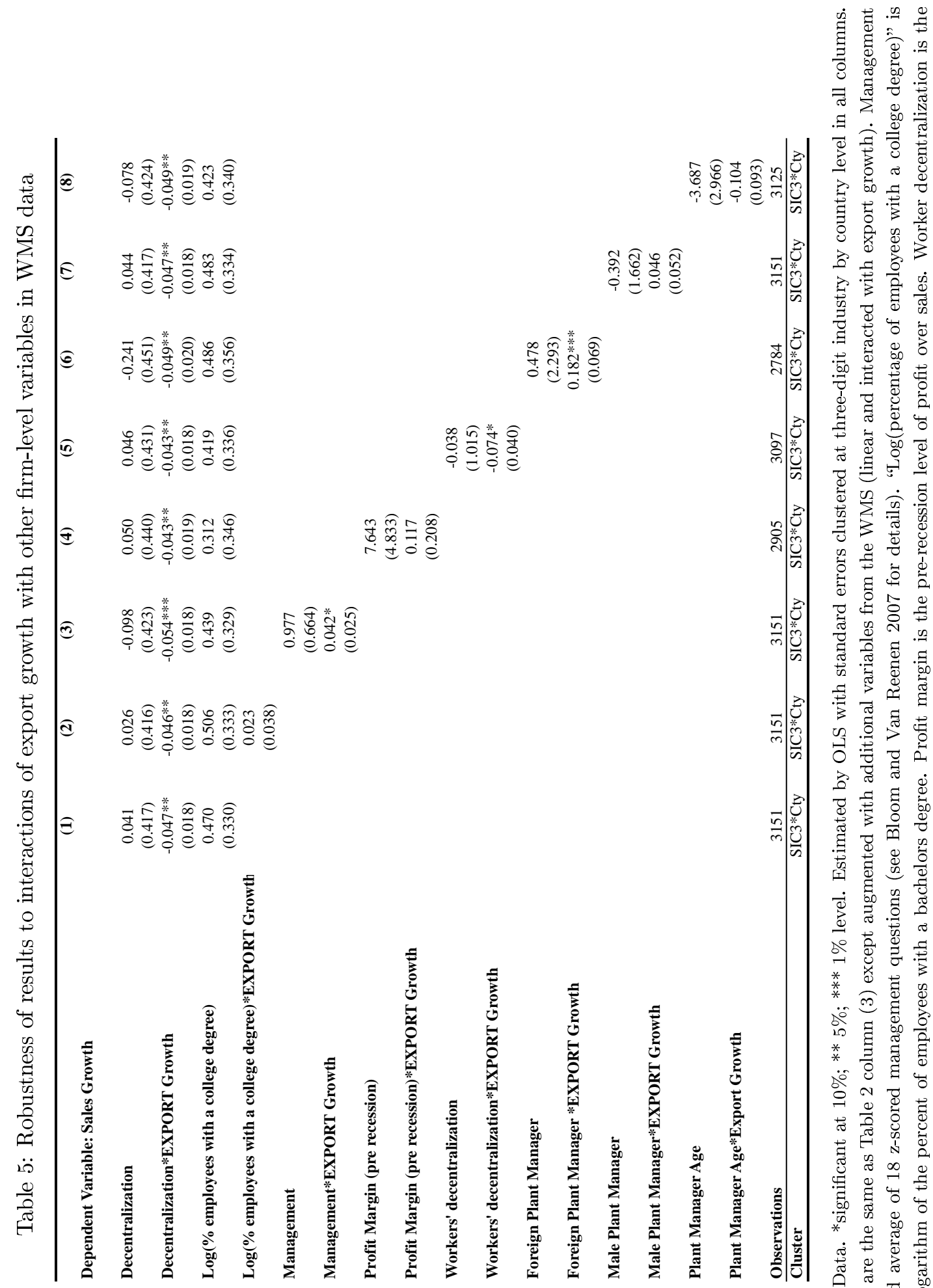

$$
\text { . }
$$

远容 80

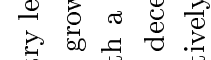

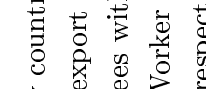
उ.

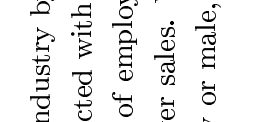

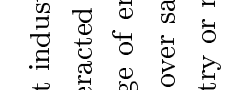

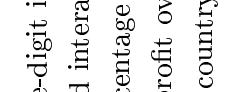

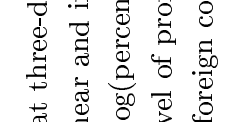
ब

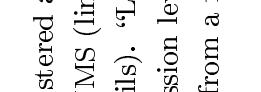

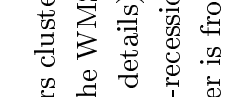

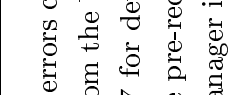

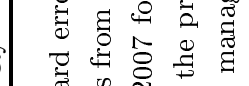
䓠

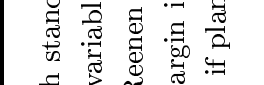
击 उ.

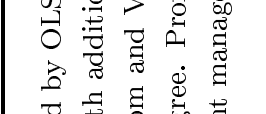

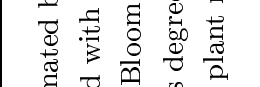

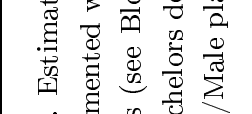

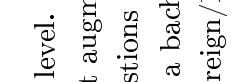

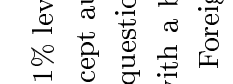
* *

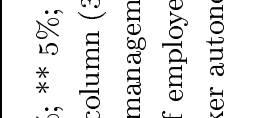

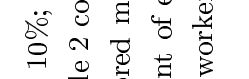

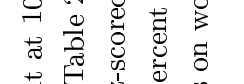

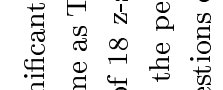

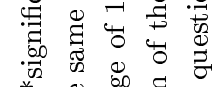
*

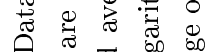

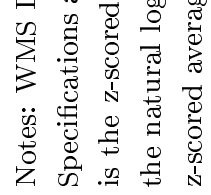



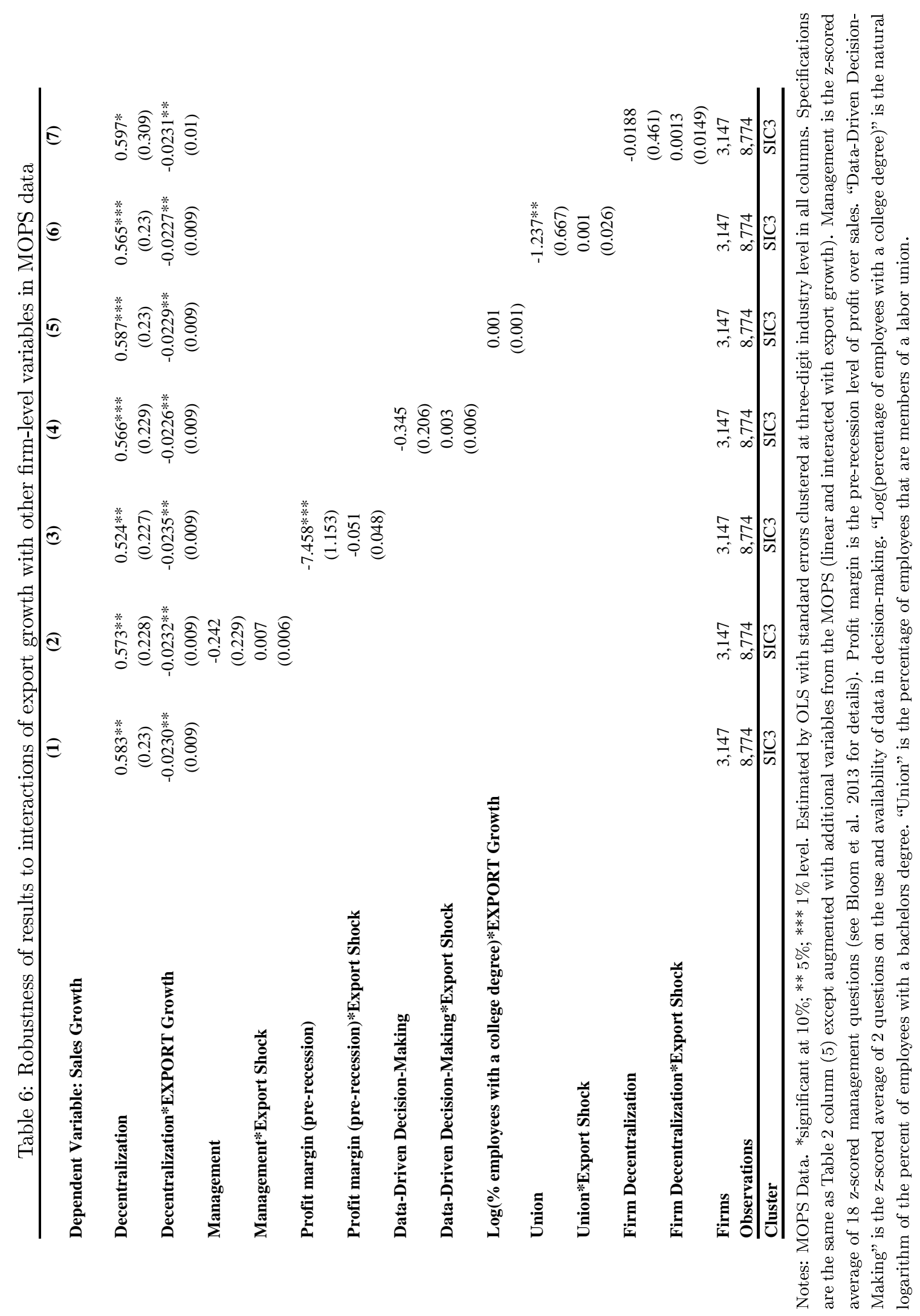


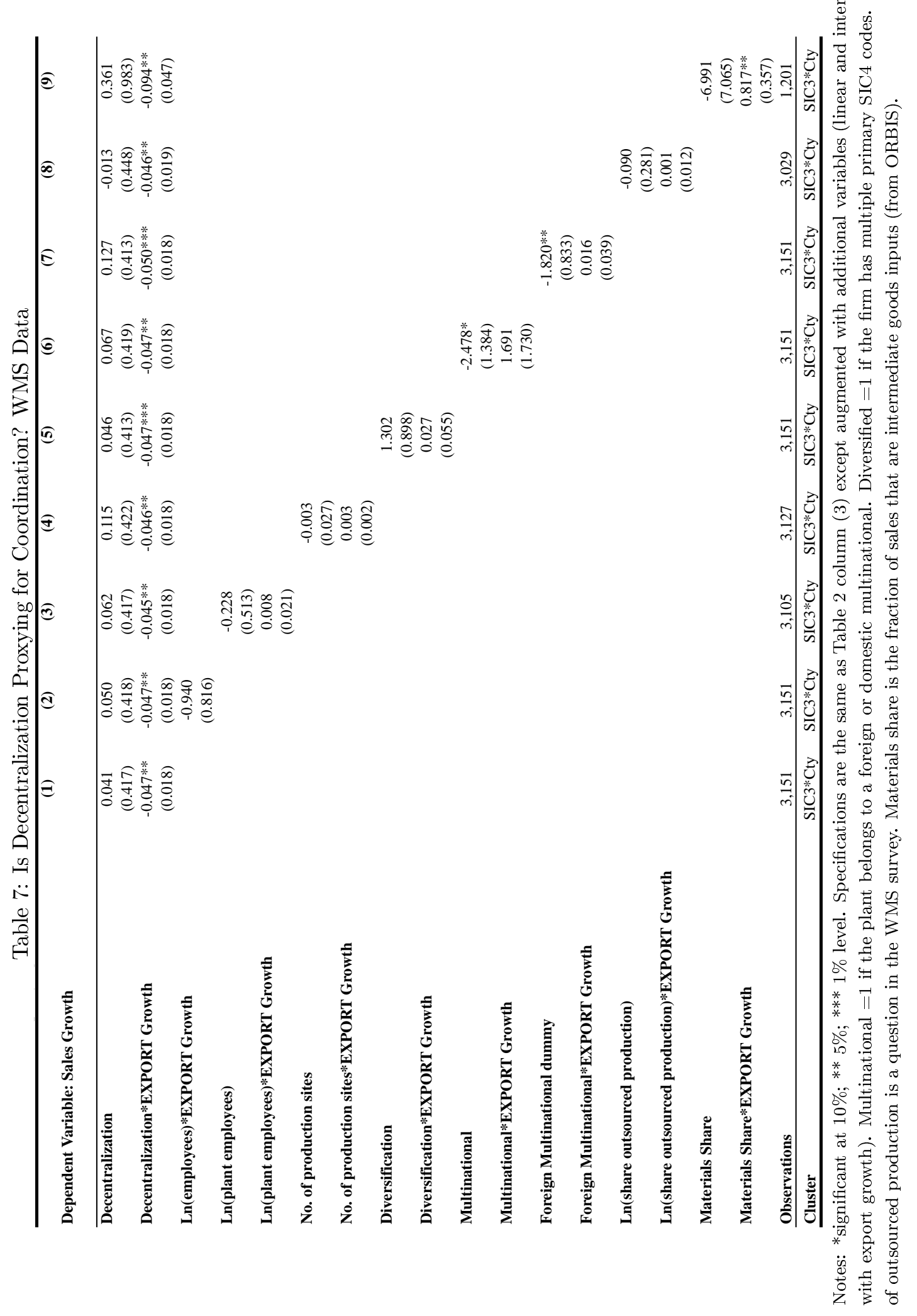




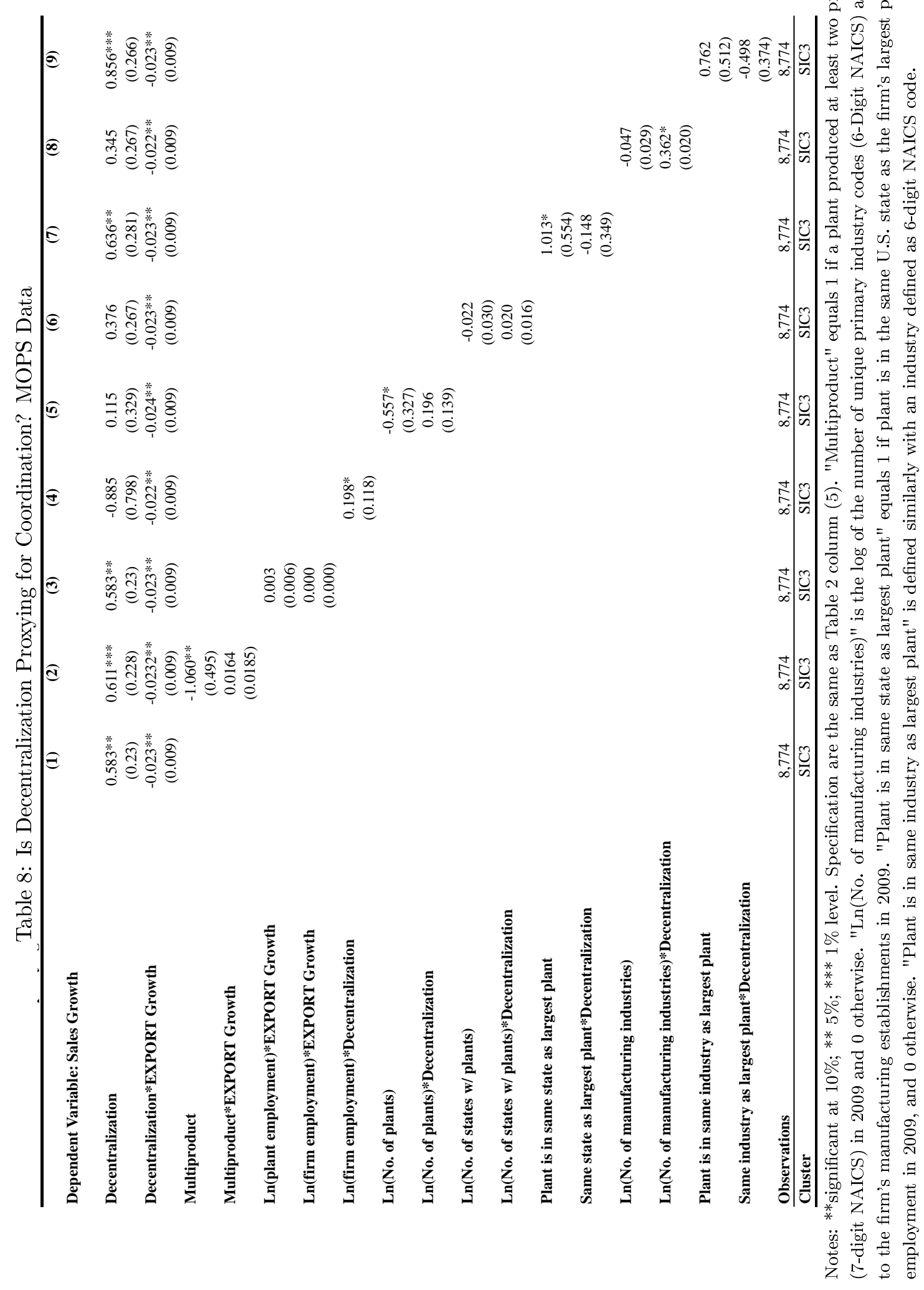




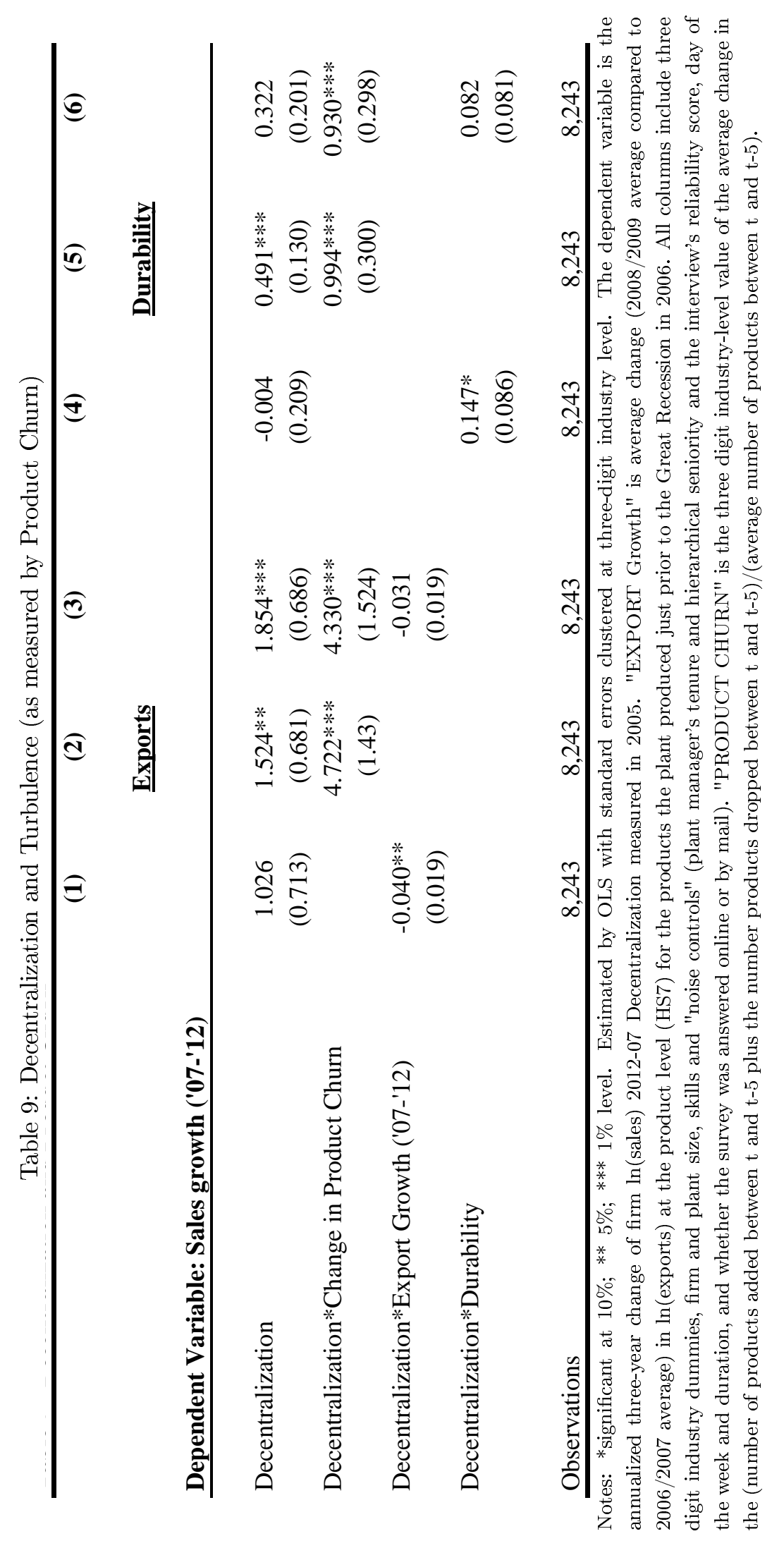




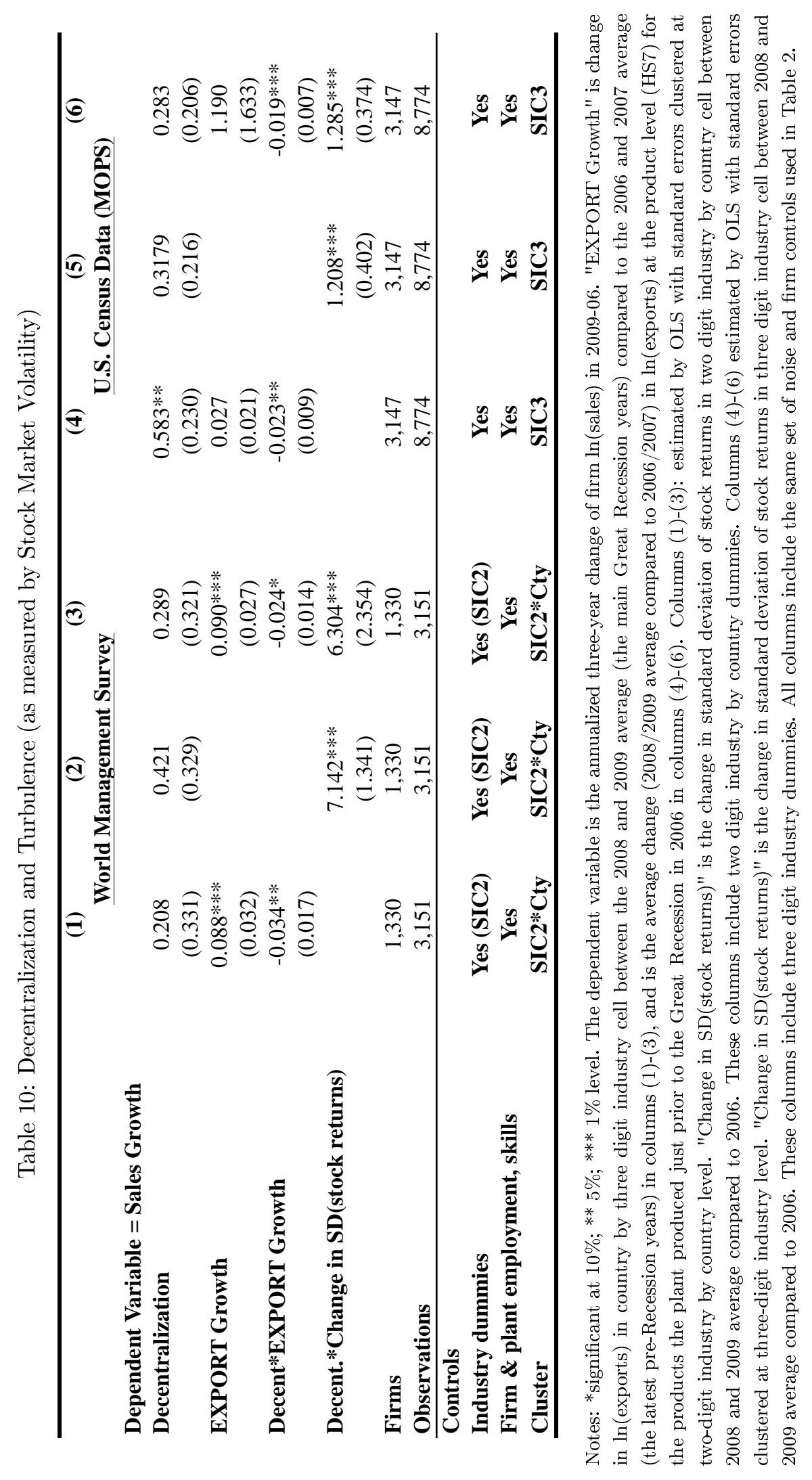




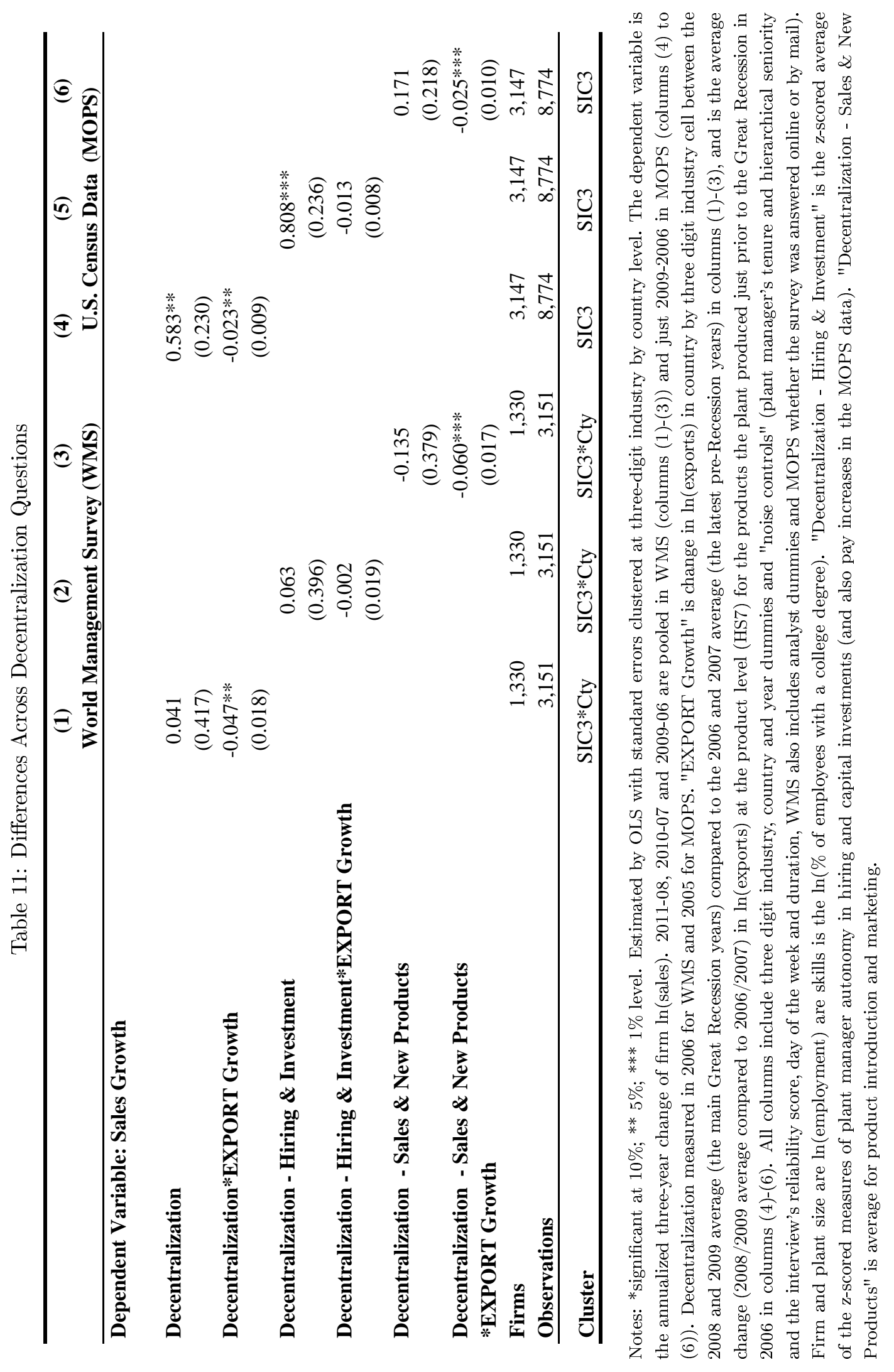




\section{Web Appendices - Not Intended for Publication}

\section{A Data Appendix}

\section{A.1 Industry-level variables}

\section{Exports}

We measure changes in exports in an industry by country cell using the UN COMTRADE database of world trade. This is an international database of six-digit product level information on all bilateral imports and exports between any given pairs of countries. We first aggregate the COMTRADE value of export data (in US dollars)from its original six-digit product level to three-digit US SIC-1987 level using the Pierce and Schott (2010) concordance. We deflate the industry and country specific export value series by a country and year specific CPI from the World Bank (2010 base year) to measure "real exports." The Export growth variable is defined as the logarithmic change in exports in 2008-09 (the average in a cell across these two Great Recession years) relative to 2006-07 (the average across the two years immediately prior to the Great Recession). The real export growth variable is winsorized at the 5 th and the 95th percentile.

\section{Durability}

Data on the average durability of the goods produced in the industry are drawn from Ramey and Nekarda (2013). This is a continuous cross-sectional measure at the 4-digit industry level.

\section{Bartik Instrument}

The Bartik IV for export growth in a country-industry cell is constructed as the change in world import demand (WID) for commodity $m$ in country $r$ between time and $t$ (2008 and 2009) and $t-1$ (2006 and 2007), is defined as:

$$
\triangle z_{m r, t}=\sum_{p} s_{m p r, t-1} * \triangle W I D_{m p r^{\prime}, t}
$$

where $s_{m p r, t-1}$ denotes the share of exports of commodity $m$ from country $r$ to partner country $p$ at time $t-1 ; W I D_{m p r^{\prime}, t}$ is the log change in total imports of commodity $c$ in partner country $p$ between $t$ and $t-1$ from all countries excluding country $r$ (hence the r'sub-script). Consider, for example, the Bartik IV for changes in US exports of anti-ulcer drugs. For a given partner, like the UK, we calculate the share of all American anti-ulcer drugs exported that were exported to the UK in $t-1$, $s_{d r u g s, U K, U S, 07-06}$, and then multiply this by the change in the imports of anti-ulcer drugs into the UK from every country

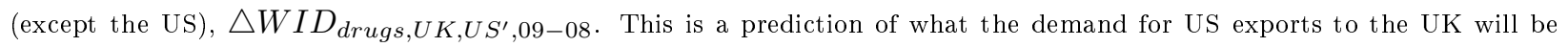
coming from exogenous world demand (rather than US specific factors). We repeat this for every country in the world (not just the UK) and then sum over all the US partner countries in the world.

Commodity $m$ is measured at the 6-digit level of the Harmonized Commodity Description and Coding System (HS). Commodity level measures are then mapped into Industry $j$ three-digit Standard Industry Classification (SIC) codes using the Pierce and Schott (2010) concordance. 


\section{A.2 World Management Survey (WMS) International Data}

\section{Firm-level Accounting Databases}

Our sampling frame was based on the Bureau van Dijk (BVD) ORBIS which is composed of the BVD Amadeus dataset for Europe (France, Germany, Greece, Italy, Poland, Portugal, and the United Kingdom); BVD Icarus for the United States, BVD Oriana for Japan. These databases all provide sufficient information on companies to conduct a stratified telephone survey (company name, address, and a size indicator). These databases also typically have accounting information on employment, sales and assets. Apart from size, we did not insist on having accounting information to form the sampling population, however. Amadeus are constructed from a range of sources, primarily the National registries of companies (such as Companies House in the United Kingdom). Icarus is constructed from the Dun \& Bradstreet database, which is a private database of over 5 million U.S. trading locations built up from credit records, business telephone directories, and direct research. Oriana is constructed from the Teikoku Database in Japan.The full WMS consists of 34 countries but because we need decentralization data in 2006 we are restricted to the 12 countries surveyed in the 2006 wave. Because we wanted to focus on mature economies we dropped China and India which left us with 10 OECD countries (France, Great Britain, Germany, Greece, Italy, Japan, Poland, Portugal, Sweden and the US).

\section{The Organizational Survey}

In every country the sampling frame for the organization survey was all firms with a manufacturing primary industry code with between 50 and 5,000 employees on average over the most recent three years of data. Interviewers were each given a randomly selected list of firms from the sampling frame. More details are available in Bloom, Sadun and Van Reenen (2012) where we compare the sampling frame with Census demographic data from each country and show that the sample is broadly representative of medium sized manufacturing firms. We also analyzed sample selection - the response rate was $45 \%$ and respondents appear random with respect to company performance, although larger firms where slightly more likely to respond. We collected a detailed set of information on the interview process itself (number and type of prior contacts before obtaining the interviews, duration, local time-of-day, date and day-of-the-week), on the manager (gender, seniority, nationality, company and job tenure, internal and external employment experience, and location), and on the interviewer (we can include individual "analyst" fixed effects, time-of-day, and subjective reliability score). We used a subset of these "noise controls" (see text) to help reduce residual variation.

In analyzing organizational surveys across countries we also have to be extremely careful to ensure comparability of responses. One step was the team all operated from two large survey rooms in the London School of Economics. Every interviewer also had the same initial three days of interview training, which provided three "calibration" exercises, where the group would all score a role-played interview and then discuss scoring together of each question. This continued throughout the survey, with one calibration exercise every Friday afternoon as part of the weekly group training sessions. Finally, the analysts interviewed firms in multiple countries since they all spoke their native language plus English, so interviewers were able to interview firms from their own country plus the UK and US, enabling us to remove interviewer fixed effects.

The construction of the degree of decentralization measures (from Central Headquarters to Plant Manager) is discussed in some detail in the text. The questions are addressed to the plant manager. We only keep observations where at least two of the four decentralization questions were answered (and we include a control for the number of non-missing questions in the set of noise controls). We drop observations where the plant manager is also the CEO (5\% of firms). In cases were the Central Headquarters is on the same site as the plant we interviewed we add a dummy variable to indicate this (one of the noise controls) to reflect potentially greater monitoring. We use the data from the 2006 wave in all cases except when we analyze changes in decentralization as an outcome where we exploit the fact that we ran another wave in 2009 and 2010 for a sub-sample of firms. 
As a check of potential survey bias and measurement error we performed repeat interviews on 72 firms in 2006, contacting different managers in different plants at the same firm, using different interviewers. To the extent that our organizational measure is truly picking up company-wide practices these two scores should be correlated, while to the extent the measure is driven by noise the measures should be independent. The correlation of the first interview against the second interviews was 0.513 (p-value of 0.000 ), with no obvious (or statistically significant) relationship between the degree of measurement error and the decentralization score. That is to say, firms that reported very low or high decentralization scores in one plant appeared to be genuinely very centralized or decentralized in their other plants, rather than extreme draws of sampling measurement error.

\section{Firm-level variables}

Our firm accounting data on sales, employment, capital (fixed assets), profits and intermediate inputs came from BVD ORBIS. Whether the variable is reported depends on the accounting standards in different countries. Sales are deflated by a three digit industry producer price index. BVD has extensive information on ownership structure, so we can use this to identify whether the firm was part of a multinational enterprise. We also asked specific questions on the multinational status of the firm (whether it owned plants aboard and the country where the parent company is headquartered) to be able to distinguish domestic multinationals from foreign multinationals.

We collected many other variables through our survey including information on plant size, skills, organization, etc. as described in the main text. We also collected management practices data in the survey. These were scored following the methodology of Bloom and Van Reenen (2007), with practices grouped into four areas: operations (three practices), monitoring (five practices), targets (five practices), and incentives (five practices). The shop-floor operations section focuses on the introduction of lean manufacturing techniques, the documentation of processes improvements, and the rationale behind introductions of improvements. The monitoring section focuses on the tracking of performance of individuals, reviewing performance, and consequence management. The targets section examines the type of targets, the realism of the targets, the transparency of targets, and the range and interconnection of targets. Finally, the incentives section includes promotion criteria, pay and bonuses, and fixing or firing bad performers, where best practice is deemed the approach that gives strong rewards for those with both ability and effort. Our management measure uses the unweighted average of the z-scores of all 18 dimensions.

Our basic industry code is the U.S. SIC (1997) three digit level-which is our common industry definition in all countries. We allocate each firm to its main three digit sector (based on sales).

\section{A.3 U.S. Census Bureau Data: MOPS}

\section{Sample}

Table A2 shows how our sample is derived from the universe of U.S. business establishments. The U.S. Census Bureau data on decentralization comes from the 2010 Management and Organizational Practices Survey (MOPS), which was a supplement to the 2010 Annual Survey of Manufactures (ASM). The MOPS survey was sent to all ASM establishments in the ASM mail-out sample. Overall, 49,782 MOPS surveys were successfully delivered, and 37,177 responses were received, yielding a response rate of $78 \%$.

The MOPS contains 36 multiple choice questions, split into 3 modules: management practices (16 questions), organization (13 questions), and background characteristics ( 7 questions). Decentralization measures come from the "Organization" module of the MOPS. Only establishments with headquarters located off-site are instructed to answer questions in the organization module. This reduces the sample to about 20,000 establishments. We also require matches to the 2006 and 2009 ASM in order to calculate the growth rates used in the analysis. This reduces the sample size substantially for two reasons. First, all of the establishments in our sample must have been operating in both 2006 and 2009. The second reason is related to the 
ASM sample design. The ASM is a rotating 5-year panel which samples large establishments with certainty but also includes a random sample of smaller establishments. The ASM sample is refreshed every five years, most recently in 2009 , thus we lose establishments which were in the 2009 and 2010 ASM samples and responded to the MOPS, but were not in the 2006 ASM sample. Finally, we require that respondents answer all 6 of the questions about decentralization (described below) and have positive value added and imputed capital in 2010. The final sample contains 8,774 establishments and 3,147 firms.

\section{Decentralization}

Our measure of decentralization is constructed from 6 questions on the MOPS (questions 18 through 23), which measure the allocation of real decision making rights between manufacturing plant managers and their central headquarters. Respondents are asked whether decisions about hiring, pay increases, product introductions, pricing, and advertising are conducted at the establishment, headquarters or both, and about the largest capital expenditure plant managers can make without authorization from headquarters. The survey asks about organizational practices in 2005 and 2010 . We use information on decentralization in 2005 in the main analysis because firms may endogenously respond to the crisis in 2010 by changing organizational structures.

Each of the 6 decentralization questions is normalized on a scale from zero to one, with one being most decentralized and zero being least decentralized. For example, question 18 reads "In 2005 and 2010, where were decisions on hiring permanent full-time employees made?" There are three possible responses: "Only at this establishment" which is assigned the value one; "Both at this establishment and at headquarters" which is assigned a value of one-half; "Only at headquarters" which is assigned a value of zero. We then standardize each question to have a mean equal to zero and standard deviation equal to one, take the mean over all six standardized questions, and then standardize this mean so that it has a mean equal to zero and standard deviation equal to one.

\section{Exports}

Our proxy for the Great Recession is a plant-specific export shock constructed by matching the product files of the 2006 ASM which disaggregate establishment revenues by product class to the Longitudinal Firm Trade Transactions (LFTTD) data which contain the universe of export shipments at the firm-product level. To construct our measure, we first match the product categories from LFTTD (ten-digit Harmonized System categories, or HS10) to the 7-digit NAICS product classes contained in the ASM using the Pierce and Schott (2009) concordance. Next, we aggregate exports to the 7-digit NAICS level and calculate the change in exports in each product over the Recession, defined as the logarithmic change in exports in 2008-09 (the average in a cell across these two Great Recession years) relative to 2006-07 (the average across the two years immediately prior to the Great Recession). Finally, we construct our plant-specific export shock as the weighted average of product export growth in the crisis, where fore each plant, the weights assigned to each product category is that plant's share of sales revenue in the product as measured before the crisis in the 2006 ASM.

\section{Product Churn}

Product churn is constructed using data come from the US Census Bureau's Census of Manufactures (CM). The CM asks establishments to list the dollar value of annual shipments by 10-digit product code. Establishments receive a list of all the product codes typically produced by establishments in their industry, along with corresponding descriptions of each code.

We start by calculating the total number of 10-digit products by each establishment in a given year, as well as the number of added products and the number of dropped products for each establishment compared to the previous CM 5 years earlier. This of course restricts the sample to manufacturing establishments which were alive five years earlier. We further restrict the sample by dropping establishments producing fewer than 3 products in both Censuses. Product churn at the establishment 
level is measured as the number of products added or dropped between the previous Census and the current Census, divided by the average number of products produced in both Censuses. That is, product churn for establishment $i$ in year $t$ is defined as:

$$
\text { Product Churn }_{i, t}=\frac{\text { Products Added }_{i, t}+\text { Products Dropped }_{i, t}}{0.5(\# \text { Products } i, t+\# \text { Products } i, t-5)}
$$

Industry product churn in year $t$ is the average establishment-level product churn amongst establishments within an industry (three digit US SIC-1987). To calculate industry-level change in product churn, we simply subtract product churn in 2007 (constructed from the product data in the 2002 and 2007 Censuses) from product churn in 2012.

\section{ASM variables}

Directly from the ASM we obtain material inputs, shipments (deflated by a three digit price deflator) as our sales measure and the headcount of employees for labor. Real capital stocks are constructed using the perpetual inventory method, following the methodology in Bloom, Floetotto, Jaimovich, Saporta-Eksten and Terry (2016). In particular, we combine detailed data on the

book value of assets every 5 years from the CM with annual investment data from the ASM. We first convert CM capital stocks from book to market value using BEA fixed asset tables. We then deflate capital stocks and investment using industry-year price indices from the NBER-CES Manufacturing Industry Database. Finally, we apply the perpetual inventory method, using the formula $K_{t}=\left(1-\delta_{t}\right) K_{t-1}+I_{t}$. This procedure is done separately for structures and for equipment. However, since the ASM contains investment broken down into investment in equipment and investment in structures, but the CM does not break down capital stocks into these two components, we must apportion plant capital stocks into each component. We do this by assigning the share of capital stock to equipment and structures which matches the share of investment in equipment and structures. 


\section{B Magnitudes}

In Table A9 we consider some simple calculations of cross-country magnitudes. Our thought experiment is to consider the Great Recession as a global shock as reflected by a fall in trade. We use the US value of the shock from COMTRADE of a fall in exports of 7.7 percent. This is the empirical difference between 2009-08 vs. 2007-06 that we use as our industry-country specific shock measure elsewhere in the paper.

We take the 2006 average levels of cross-country decentralization by country (column (1) of Table A9) and the empirical estimates in column (2) of Table 2 to estimate the average annual implied effect of GDP of the shock (column (2) of Table A9). We express this relative to the US in column (3). For all countries except Sweden there is a negative relative implied effect because decentralization in the US is greater than every other country except Sweden. Column (4) displays the actual annual change in GDP growth since the start of the global financial crisis (from World Bank data) for each of our countries and then again expresses these relative to the US base in column (5). Every country except Poland (which is still in a strong catch-up phase of development) experienced a slower growth performance than the US over this period, averaging just over a third of a percentage point (base of column). Column (6) divides the column (3) into column (5) which is the fraction of relative economic performance accounted for by decentralization (note that since we are assuming a common shock, none of this difference is due to the magnitude of the crisis being worse in some countries than others).

Overall, column (6) of Table A9 suggests that an average of $15 \%$ of the post-crisis growth experience between countries is accounted for by decentralization. This is non-trivial as mentioned in the text, but it is worth noting that there is a large degree of heterogeneity between countries underneath this average. Almost all of the differential growth experience of France and Japan compared to the US can be accounted for by decentralization (96\% and 95\% respectively), whereas decentralization accounts for virtually none of the UK's performance. In particular, as noted above, because Sweden is more decentralized than the US we should expect it to have outperformed the US, whereas it grew about half a percentage point more slowly. If we drop Sweden, the importance of decentralization doubles to accounting for almost a third of the difference (32\%). Note that the contribution is also negative for Poland, because although Poland is more centralized than the US, it grew more quickly over this time period. 
Figure A1: Change in Industry/Country Exports and Sales before and after the Great Recession

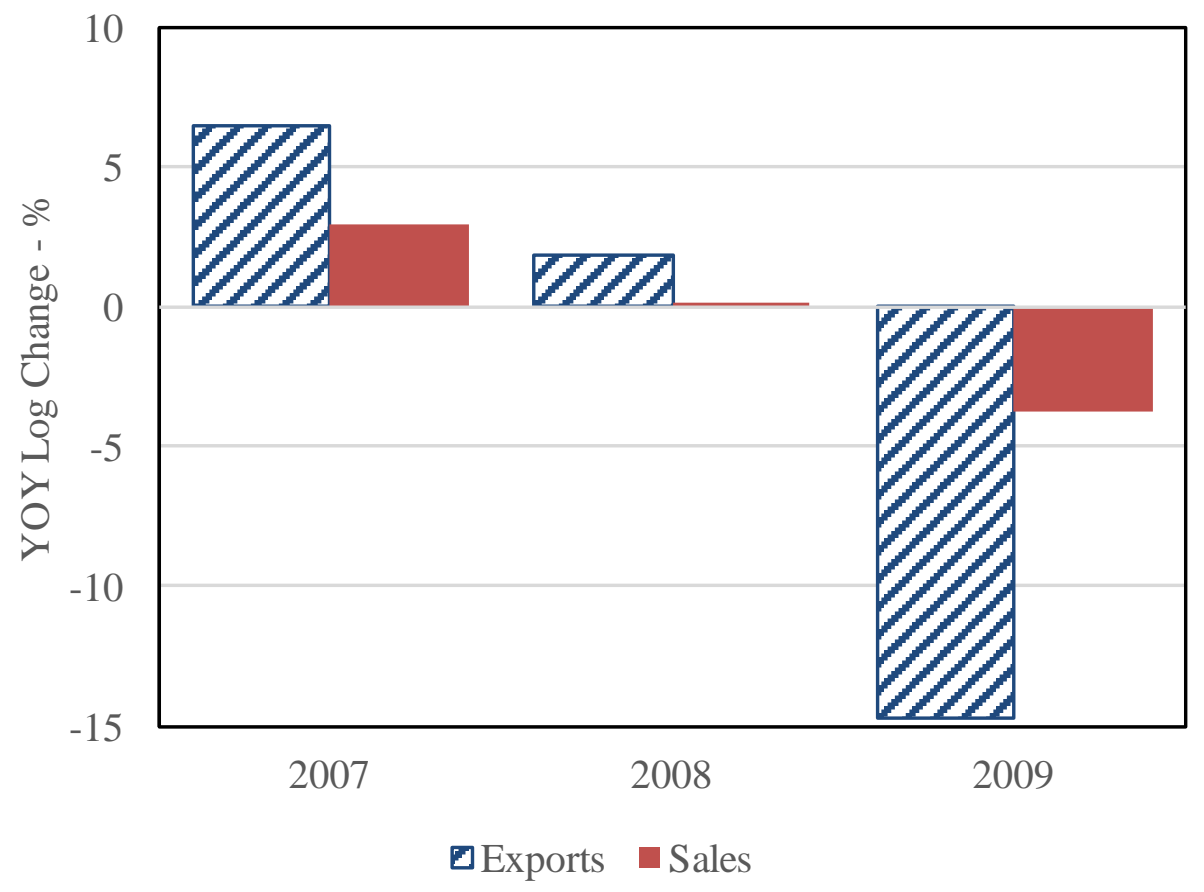

Notes: Each bar plots the yearly percentage change in real manufacturing exports. The countries included in the sample are France, Germany, Greece, Italy, Japan, Poland, Portugal, Sweden, UK and US. 
Figure A2: Average Decentralization Z-score by Quintile of Product Churn

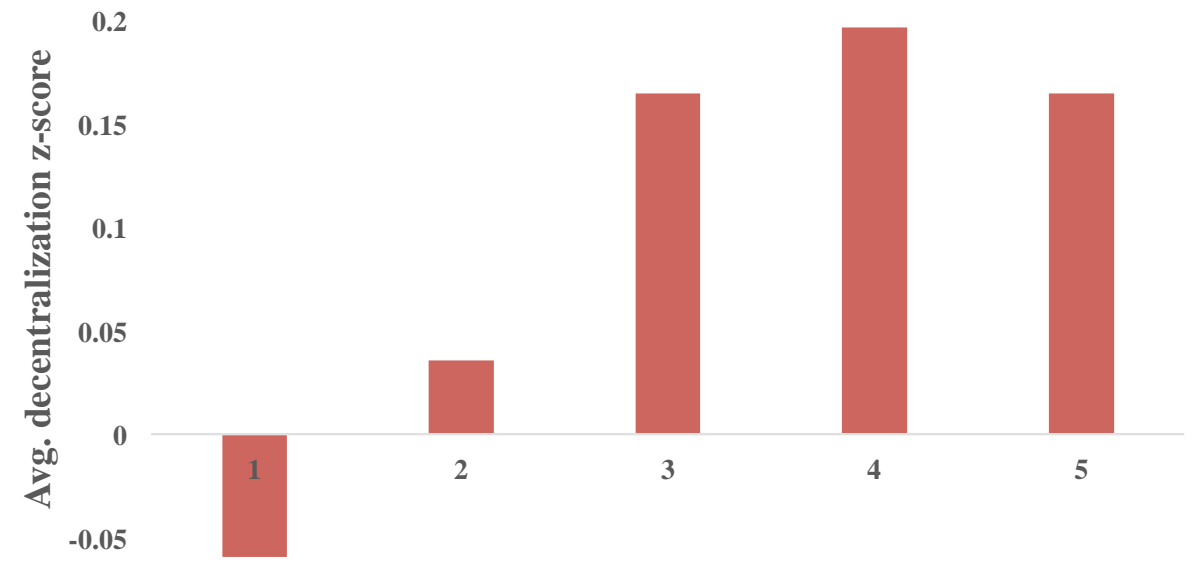

$-0.1$

\section{Quintile of product churn}

Notes: MOPS data. Industry product churn is the average of plant product churn. Plant product churn $=(\#$ products added from '02 to '07 + \# products dropped from '02 and '07)/(0.5*\# products produced in '02 + 0.5*\# products produced in '07). 
Figure A3: Change in Industry Product Churn and Export Growth

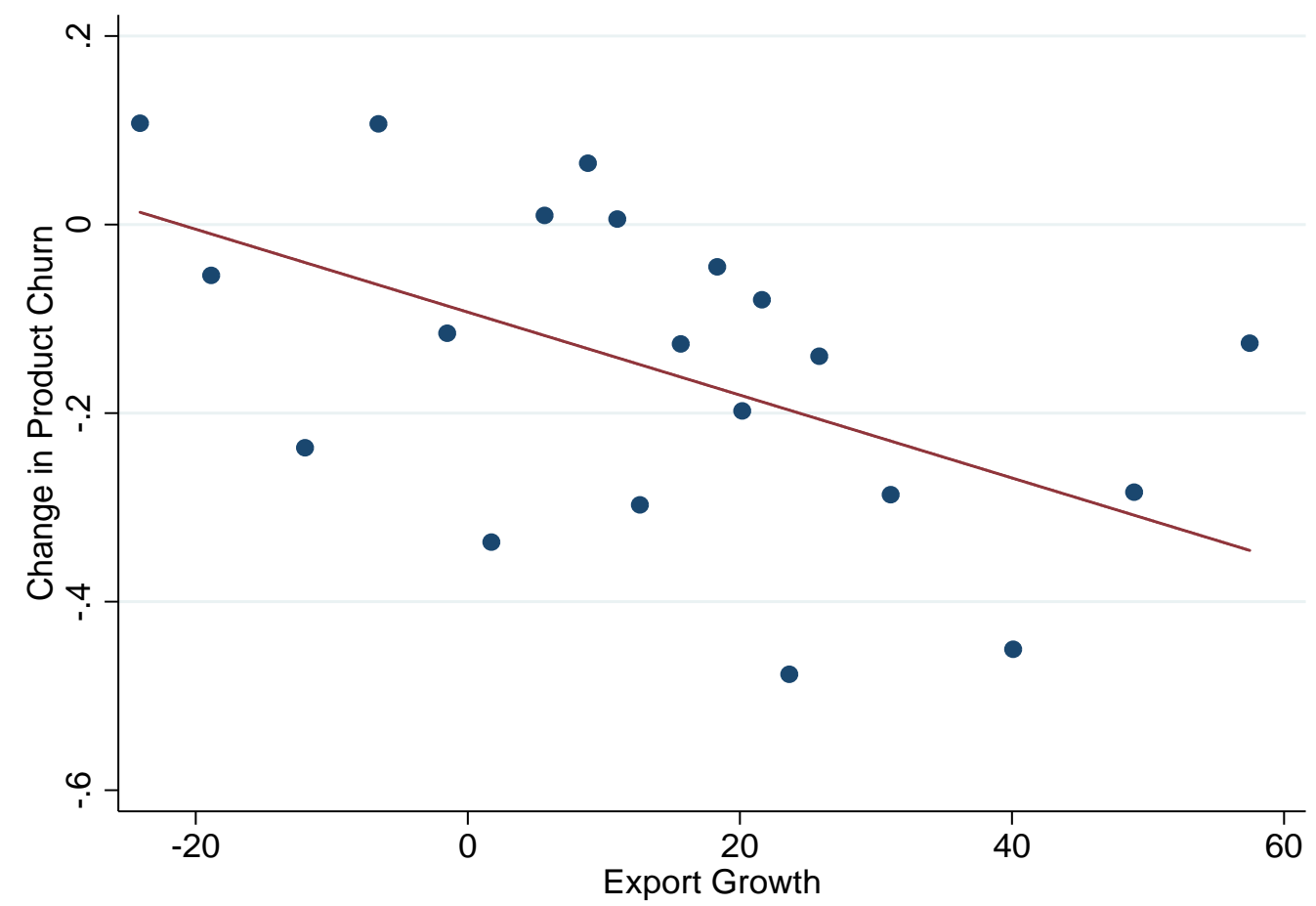

Notes: MOPS data. Change in product churn is industry product churn in 2012 minus industry product churn in 2007. Exports growth is the change in $\ln$ (exports) from 2007 to 2012. Both variables are winzorized at the 5th and 95th percentiles and measured at the level of the three-digit industry. Vingtiles plotted. 


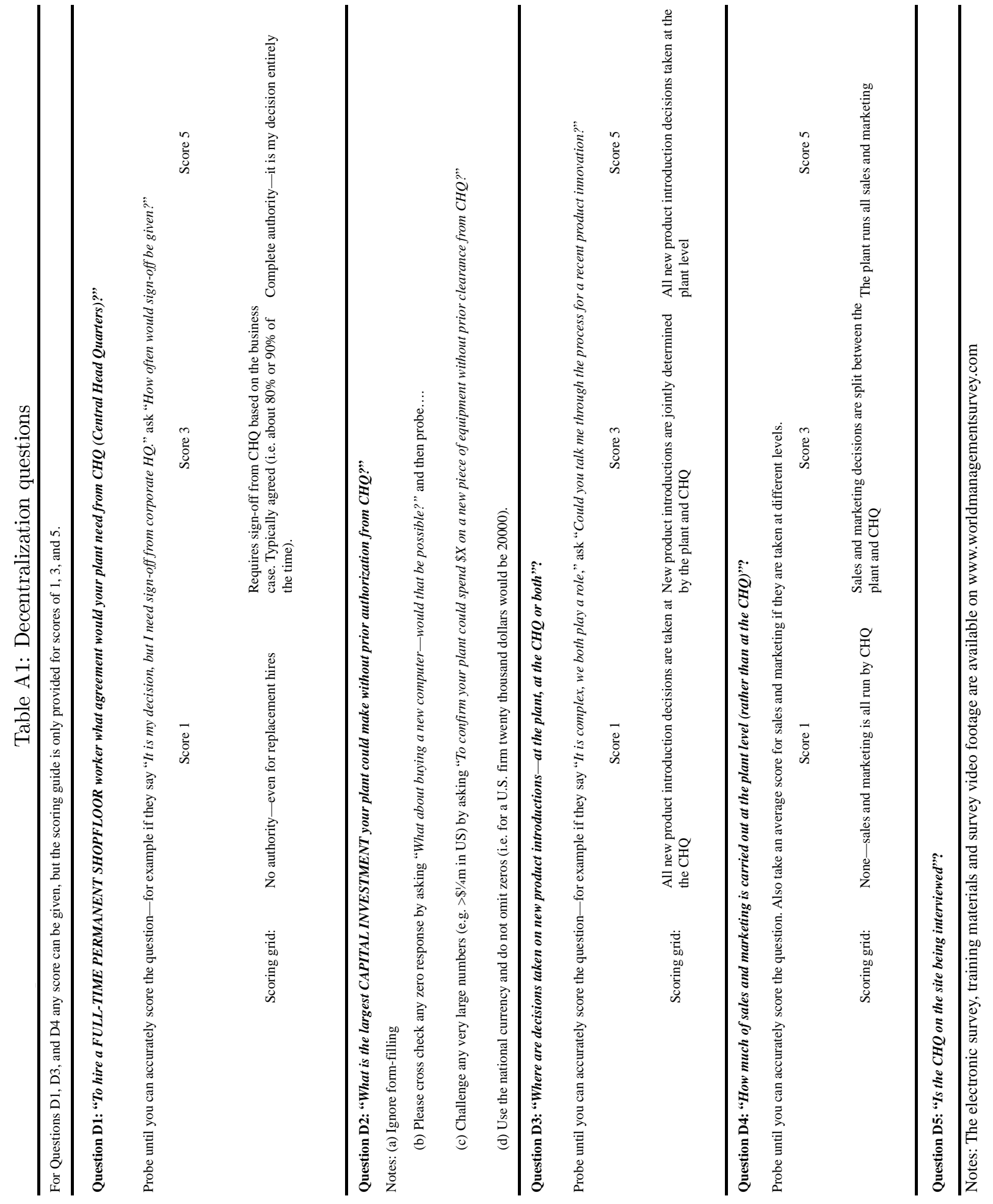




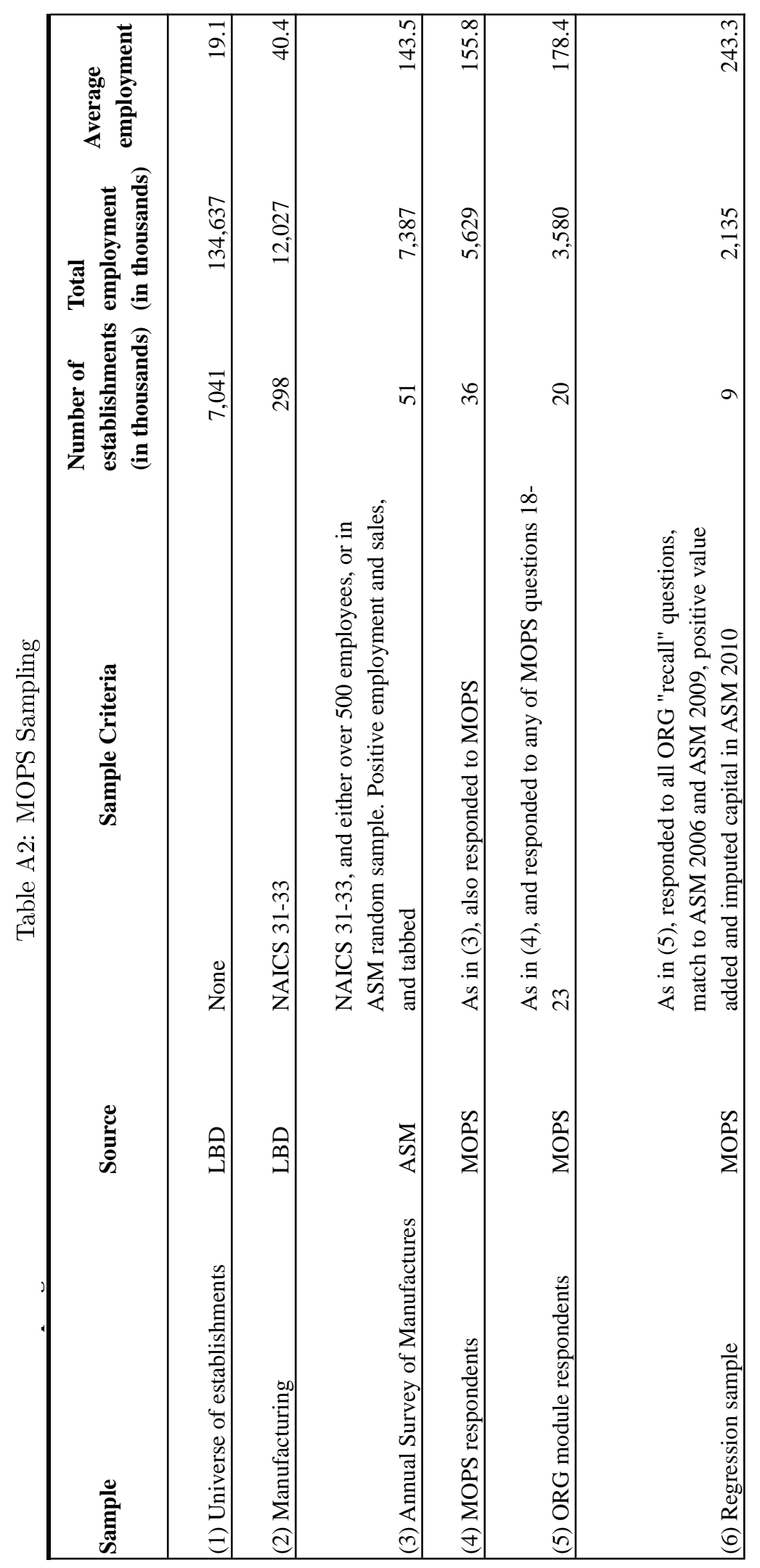




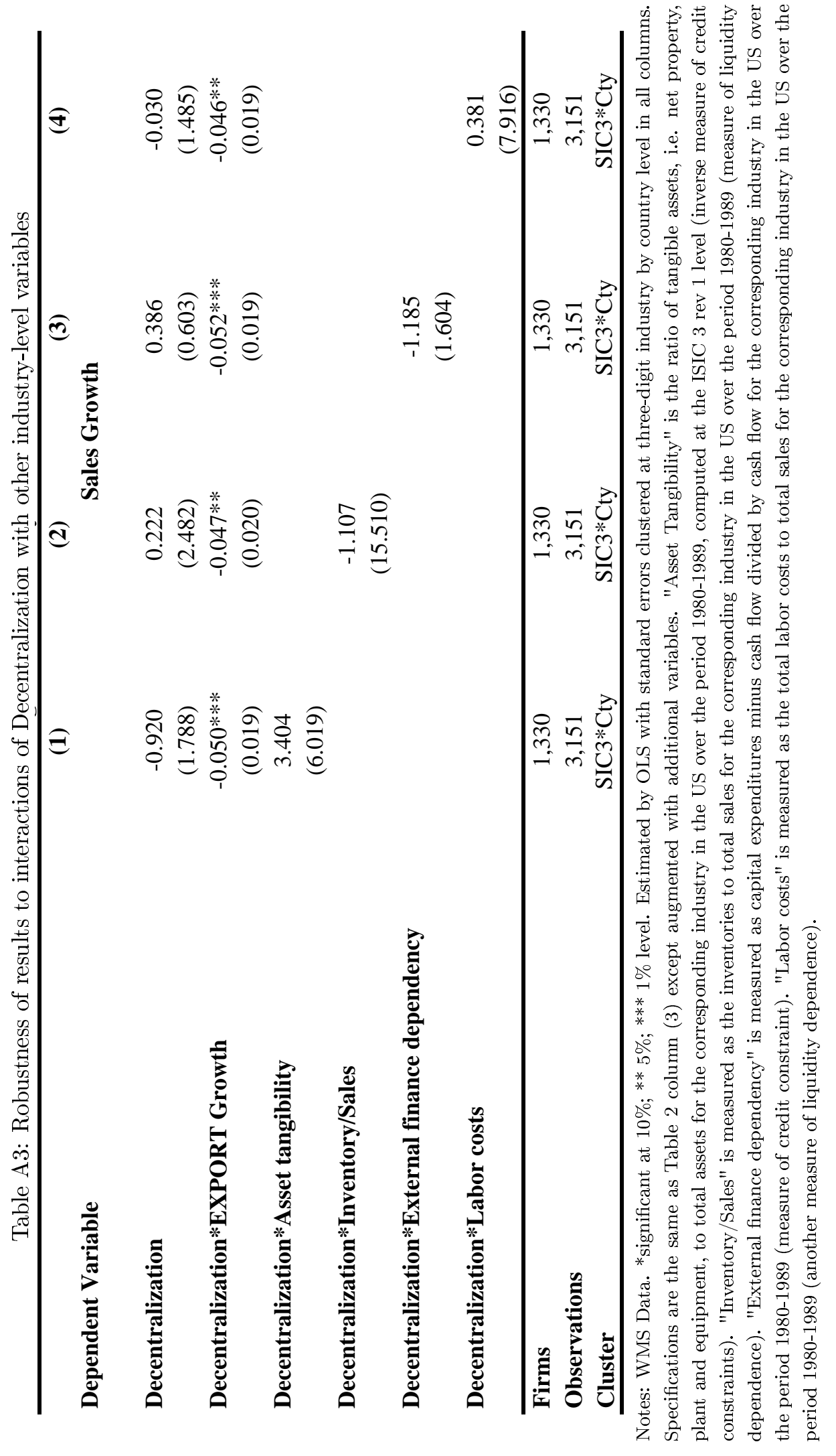




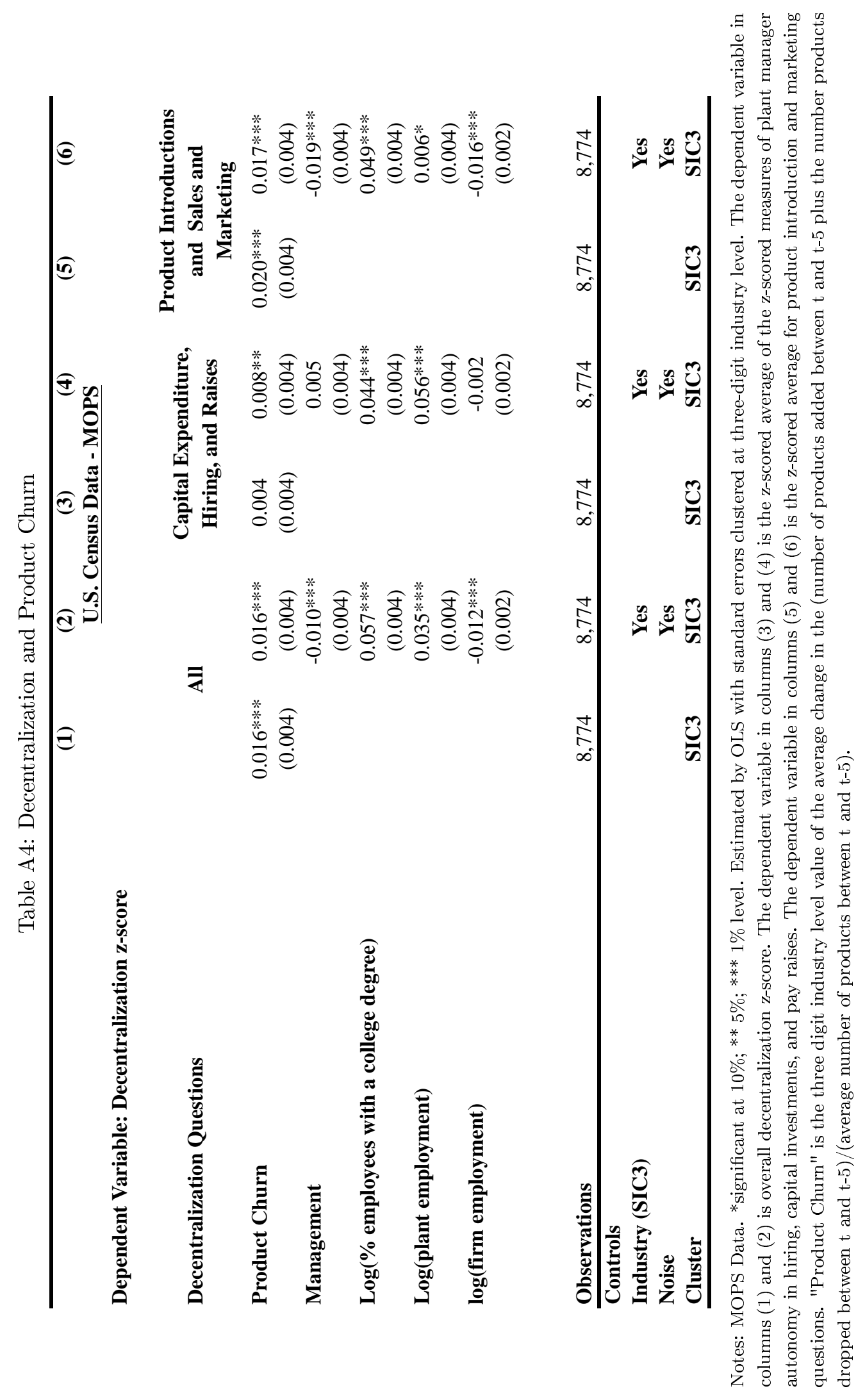




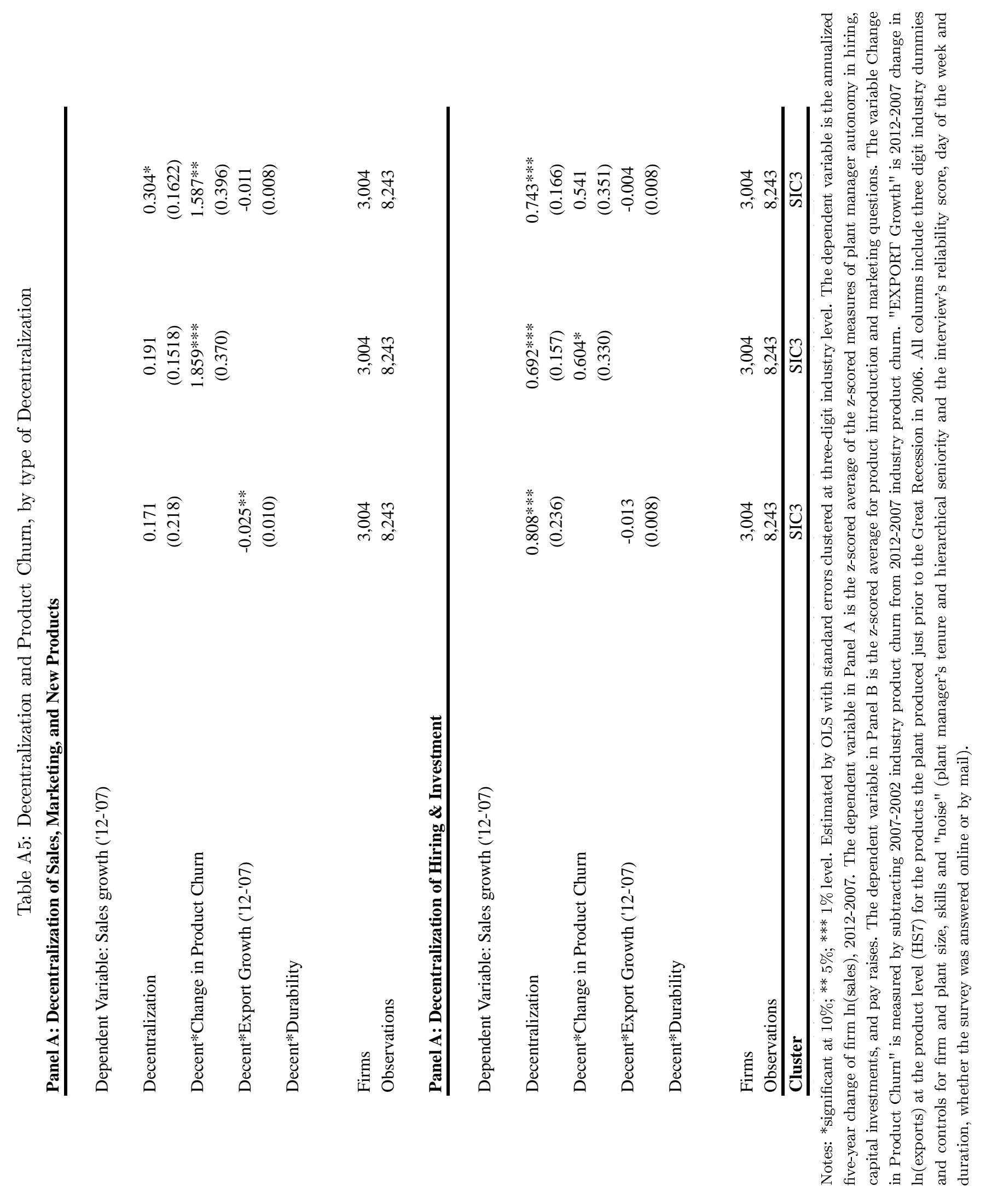




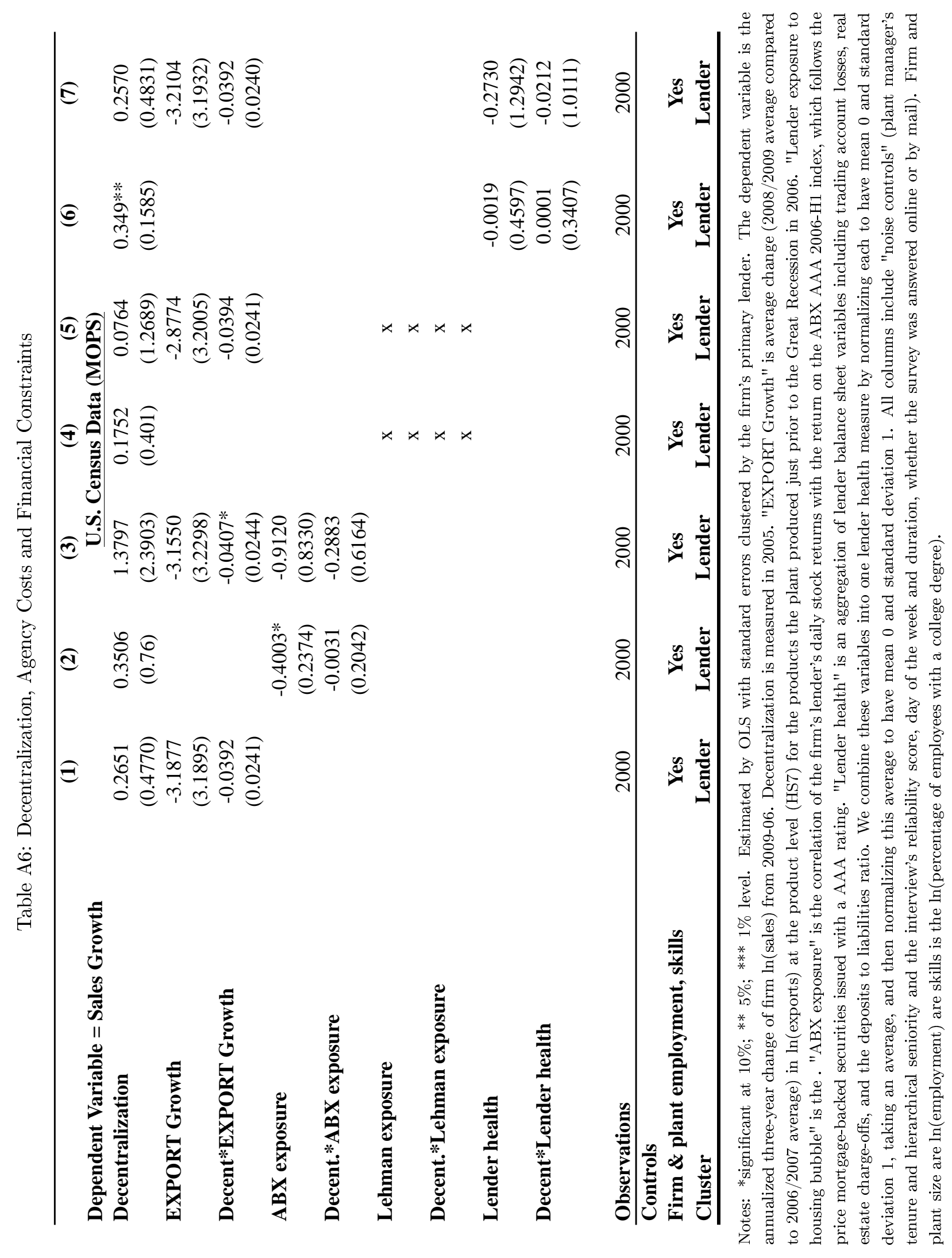




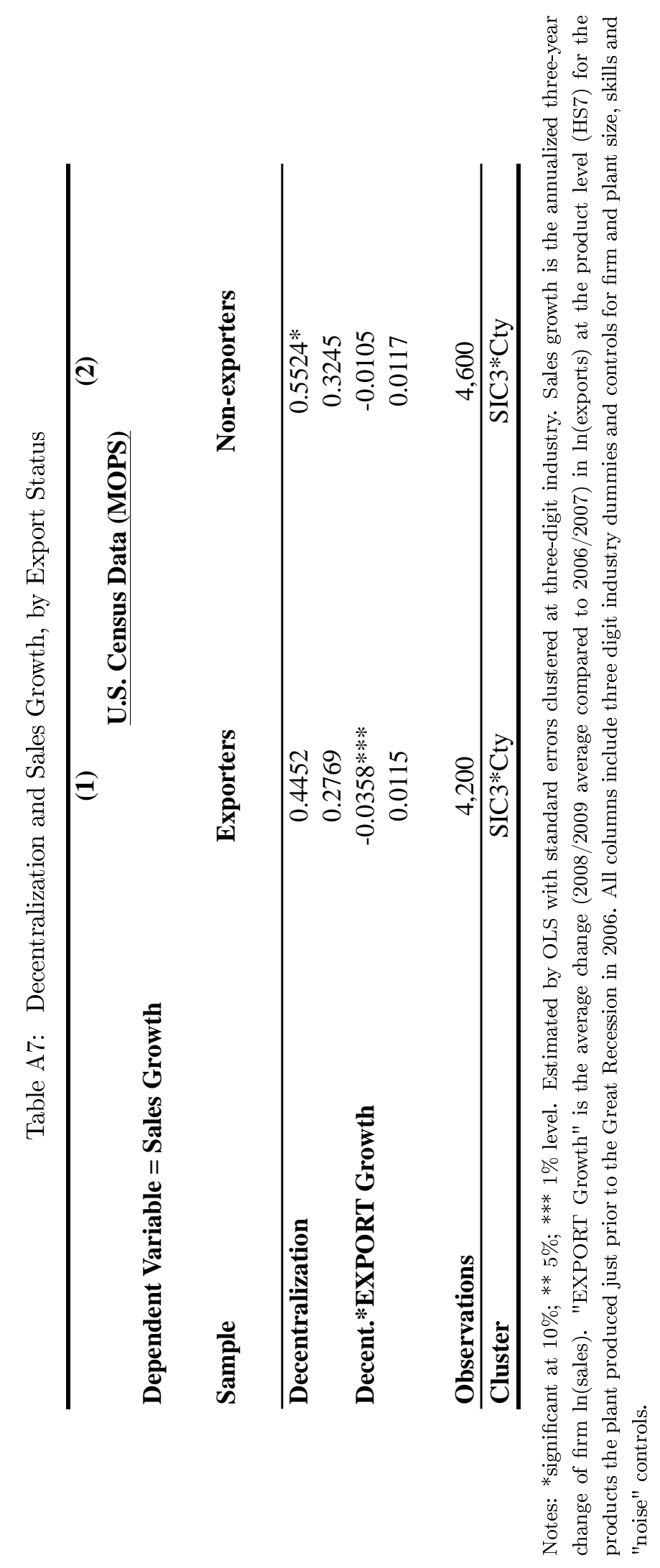




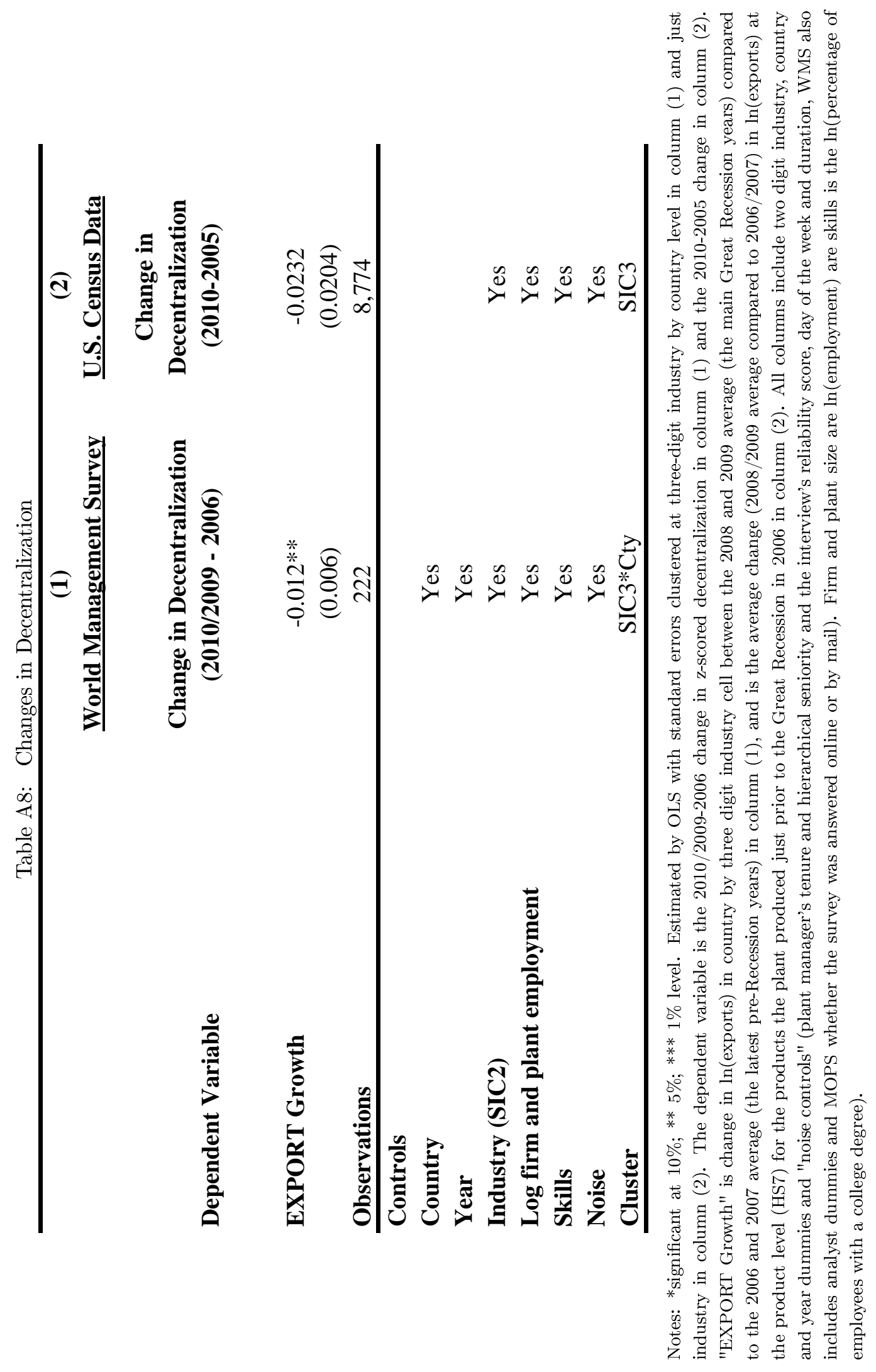




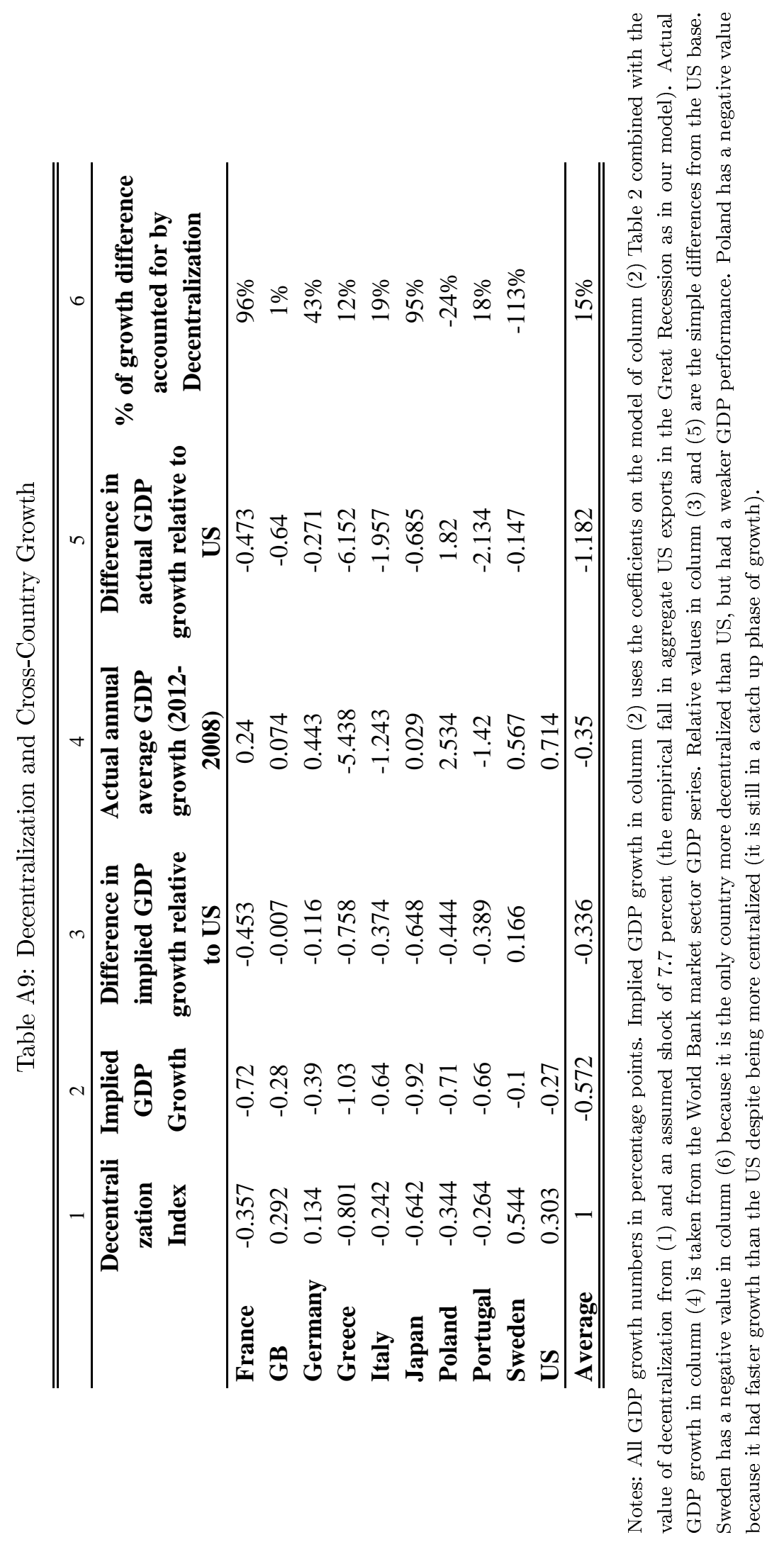

